\title{
A scalable and spatiotemporally resolved agricultural life cycle assessment of California almonds
}

\author{
Elias Marvinney ${ }^{1} \cdot$ Alissa Kendall $^{1}[\mathbb{C}$
}

Received: 12 May 2020 / Accepted: 18 March 2021 / Published online: 31 March 2021

(c) The Author(s) 2021

\begin{abstract}
Purpose California's Central Valley produces more than $75 \%$ of global commercial almond supply, making the life cycle performance of almond production in California of global interest. This article describes the life cycle assessment of California almond production using a Scalable, Process-based, Agronomically Responsive Cropping System Life Cycle Assessment (SPARCS-LCA) model that includes crop responses to orchard management and modeling of California's water supply and biomass energy infrastructure.

Methods A spatially and temporally resolved LCA model was developed to reflect the regional climate, resource, and agronomic conditions across California's Central Valley by hydrologic subregion (San Joaquin Valley, Sacramento Valley, and Tulare Lake regions). The model couples a LCA framework with region-specific data, including water supply infrastructure and economics, crop productivity response models, and dynamic co-product markets, to characterize the environmental performance of California almonds. Previous LCAs of California almond found that irrigation and management of co-products were most influential in determining life cycle $\mathrm{CO}_{2}$ eq emissions and energy intensity of California almond production, and both have experienced extensive changes since previous studies due to drought and changing regulatory conditions, making them a focus of sensitivity and scenario analysis.

Results and discussion Results using economic allocation show that $1 \mathrm{~kg}$ of hulled, brown-skin almond kernel at postharvest facility gate causes $1.92 \mathrm{~kg} \mathrm{CO}_{2} \mathrm{eq}\left(\mathrm{GWP}_{100}\right), 50.9 \mathrm{MJ}$ energy use, and $4820 \mathrm{~L}$ freshwater use, with regional ranges of 2.0-2.69 $\mathrm{kg} \mathrm{CO}_{2} \mathrm{eq}, 42.7-59.4 \mathrm{MJ}$, and 4540-5150 L, respectively. With a substitution approach for co-product allocation, $1 \mathrm{~kg}$ almond kernel results in $1.23 \mathrm{~kg} \mathrm{CO}_{2} \mathrm{eq}, 18.05 \mathrm{MJ}$ energy use, and $4804 \mathrm{~L}$ freshwater use, with regional ranges of $0.51-1.95 \mathrm{~kg} \mathrm{CO}_{2}$ eq, 3.68-36.5 MJ, and 4521-5140 L, respectively. Almond freshwater use is comparable with other nut crops in California and globally. Results showed significant variability across subregions. While the San Joaquin Valley performed best in most impact categories, the Tulare Lake region produced the lowest eutrophication impacts.

Conclusion While $\mathrm{CO}_{2}$ eq and energy intensity of almond production increased over previous estimates, so too did credits to the system for displacement of dairy feed. These changes result from a more comprehensive model scope and improved assumptions, as well as drought-related increases in groundwater depth and associated energy demand, and decreased utilization of biomass residues for energy recovery due to closure of bioenergy plants in California. The variation among different impact categories between subregions and over time highlight the need for spatially and temporally resolved agricultural LCA.
\end{abstract}

Keywords Almond $\cdot$ Carbon footprint $\cdot$ Bioenergy $\cdot$ Irrigation $\cdot$ LCA $\cdot$ California $\cdot$ Perennial

\section{Introduction}

\subsection{Background}

Communicated by Greg Thoma.

Alissa Kendall

amkendall@ucdavis.edu

1 Department of Civil and Environmental Engineering, University of California Davis, Davis, CA, USA
Globally, 1.3 million metric tons of almond kernel were produced in 2017, with California production account ing for more than $75 \%$ thereof. Some 675,000 metric tons were exported from California, primarily to the European Union, China, and India (USDA 2017). In 2017, almond acreage 
in California exceeded 538,000 ha with approximately 404,000 ha of bearing age (CDFA 2018).

Almonds are produced from a perennial tree crop with a productive lifespan of anywhere from 15 to 30 years, typically estimated at about 25 years in California. They are grown under intensive conditions in California's Central Valley (CV), demanding significant quantities of inputs such as water and fertilizer, and producing exceptionally high yields (Duncan et al. 2016; Pope et al. 2016; Yaghmour et al. 2016). In addition to almond kernel, orchards generate hulls, shells, and orchard biomass as co-products or by-products. These products have found varied and changing uses over time, and previous life cycle assessments (LCAs) found that their use and management significantly affect the environmental intensity of almond production (Kendall et al. 2015; Marvinney et al. 2015).

The environmental impacts and benefits of California almonds have previously been characterized using LCA, but with data representative of conditions prior to an intense drought (between 2011 and 2015) and a limited scope of modeling and impact assessment categories (Kendall et al. 2015; Marvinney et al. 2015). These analyses found that orchard irrigation and end-of-life (EoL) biomass management were the main drivers of net greenhouse gas (GHG) emissions and energy use. Since these publications, the almond production landscape in California has changed significantly_particularly due to ongoing biomass power plant idling and closure resulting in reduced opportunities for bioenergy production from orchard biomass, as well as an increase in groundwater-based irrigation pumping and aquifer depth driven by drought conditions.

While the literature on LCA applied to agricultural systems and food products is very extensive, the work dedicated to tree crops, and nuts in particular, is not. Perhaps the most extensively studied tree crops are apple (Alaphilippe et al. 2016; Longo et al. 2017; Bartzas et al. 2017; Milà et al. 2006), citrus (Beccali et al. 2010; Nicolò et al. 2018; Giudice et al. 2013; Sanjuán et al. 2005), and peach (Ingrao et al. 2015; Winans et al. 2020; De Menna et al. 2015; Nikkhah et al. 2017). A few studies have examined almond and other nut crops (Bartzas and Komnitsas 2017; Rosa et al. 2017; Volpe et al. 2015). Bartzas et al. (2017) compared pistachio, almond, and apple production in Greece to LCAs from other parts of the world, and bolstered earlier findings (e.g., Kendall et al. 2015) that the largest contributors to global warming intensity were irrigation and nutrient management.

Researchers have also considered the particular requirements for undertaking LCAs of perennial systems and tree crops. Bessou et al. (2016) showed that studies that omit the full orchard life cycle fail to accurately assess the impacts of production. Raschio et al. (2018) had similar findings, and also showed the importance of spatial specificity. In their comprehensive meta-analysis of global cropping systems,
Poore and Nemecek (2018) highlighted the potential benefits from land use change in woody perennial crops, further demonstrating the importance of using spatially resolved data in perennial crop LCA.

This article describes the development of an LCA of California almond production systems based on a Scalable, Process-based, Agronomically Responsive Cropping System Life Cycle Assessment (SPARCS-LCA) model. The research and modeling approach responds to many of the findings of previous work by developing a regionalized, spatially explicit LCA modeling approach for California cropping systems, to enhance understanding of the regional differences in environmental intensity of almonds, to identify the important drivers for environmental impact (including changing environmental conditions due to drought), and to identify opportunities for improvement. The term "scalable" refers to the SPARCS-LCA models capability of conducting a process-based LCA at the orchard, county, hydrologic region, growing region, or state scale. "Spatio-temporally resolved" refers to the explicit modeling of orchard age by location. The mechanisms for achieving these goals include enhanced spatial detail, and up-to-date resource and market condition data, as well as incorporation of crop agronomic responses to management and input changes.

\section{Methods and materials}

\subsection{Goal and scope of the model}

This work aims to develop an LCA model of California almond production that captures variability in cropping systems over space and time. Key attributes include accounting for the effects of changing environmental (e.g., water availability for irrigation) and industrial conditions (e.g., the siting or closure of biomass energy facilities), as well as the changing location and extent of cultivation, embedded crop responses (yield and biomass production) to agronomic and management practices, and consideration of the changing fates of orchard co-products (Section S1, Supplementary Information). The reported functional unit is $1 \mathrm{~kg}$ of raw brown skin almond kernel, but the model is designed to report results in other plausible functional units including hectares, kilocalories, or specific nutritional values.

Almond production generates by-products and coproducts (referred to collectively as co-products) alongside almond kernel. Conforming to the attributional nature of this LCA, economic allocation is used to apportion impacts to almonds as a baseline approach. Other partition-based allocation methods, such as those based on mass or energy content, attribute the majority of impacts to woody biomass generated from almond orchards and do not reflect the drivers for the almond production system. To deepen 
understanding of the environmental and resource implications of almond co-products and inform decision-making around co-product fates, a substitution (i.e., displacement) approach is also tested. This provides particular insights for orchard biomass which is used in bioenergy generation but has no economic value. Despite the fact that practice and policy have often applied substitution-based allocation in attributional contexts, the debate on using substitutionbased allocation in attributional LCA has long held that it constitutes an incontrovertible inconsistency and should not be done (e.g., Majeau-Bettez et al. 2018). However, here substitution-based allocation provides insights unavailable from partition-based allocation methods and can be viewed in a consequential context around decisionmaking about how to utilize co-products given evolving priorities, markets, and policies that shape industry-wide and grower decisions.

The TRACI 2.1 impact assessment method is used to characterize the following impact categories; global warming for 20- and 100-year timeframes, total primary energy use, smog formation, ozone depletion, human health particulate, acidification, eutrophication, fossil fuel use (USEPA 2017). Two non-TRACI impact categories were also included; total freshwater use and the AWARE water scarcity indicator (WULCA 2018).

Perennial crops have multi-year to multi-decade lifespans, and as such require explicit accounting for temporal variation in production characteristics (illustrated in Fig. S2 of the supplementary material). The orchard life cycle is organized into distinct developmental stages: nursery production and sapling planting, establishment, growth, maturity, decline, and EoL—each of which entails a unique combination of tree physiological characteristics, input demands, and management operations. The scope of this analysis includes orchard establishment (including nursery production) through orchard end-of-life (tree removal and one fallow year), a total time period of 19-24 years, under California cultivation conditions for the three primary growing regions in the state leading up to the year 2018. Temporally variable data such as groundwater level and kernel price make use of 5-year mean values (2013-2018).

Given the intense scrutiny that almond production and the agriculture sector as a whole have received in post-drought California and given increased interest by retailers and consumers in understanding the impacts of food and diet choices, the audience of this study includes producers, retailers, and consumers, as well as relevant research communities. Study results are intended to support industry efforts towards sustainability (ABC 2019), demand for environmental labeling in foreign markets (Del Borghi 2013; EPD International 2020), and policy efforts for environmental regulation (CDFA 2020; California State Assembly 2006).

\subsection{System definition, boundaries, and model assumptions}

Because this LCA attempts to characterize almond production across the state of California, the systems that comprise the background and foreground of almond production are conceived at three scales: global background processes (e.g., nitrogen fertilizer production), which rely on reference LCIs from commercial databases; regional processes (e.g., sapling production or transportation of inputs and outputs from the orchard and post-harvesting sites), which rely largely on modeling or primary data collection; and the orchard agroecosystem (e.g., on-field operations and tree growth), which are also largely modeled processes. Figure 1 illustrates key processes within each of these scales, differentiating between physical flows, processes happening over time (temporal flows), and carbon pools. The system boundary is also included, showing that value-added processing, distribution, and consumption are not included in this assessment. Section S1 in the Supplementary Material provides additional information on the data structure and sources used in the SPARCS-LCA model.

The three major hydrologic/growing regions of California's CV are included in the model: the Sacramento Valley (SV), San Joaquin Valley (SJV), and Tulare Lake (TL) regions (Fig. 2). Each of the modeled regions has distinct infrastructure, agronomic, and environmental conditions that affect input demands, management operations, and orchard productivity. For example, the SV region is generally characterized by greater water availability throughout the growing season, resulting in less demand on groundwater resources and lower energy consumption for irrigation. The SJV region is characterized by longer orchard lifespans and a greater availability of bioenergy facilities to act as a sink for EoL biomass byproduct, while the TL region is characterized by higher water and nutrient demand and higher annual kernel yields. The geographic scale of this analysis is driven by technology and management practice adoption (including irrigation system, water source, nutrient and pest management choices), which is in turn driven by the general environmental and growing conditions that characterize these three regions.

\subsection{Description of orchard life cycle and business-as-usual conditions}

The life cycle of an orchard begins with sapling production at a nursery, and a fallow year between orchard plantings (year 0). Planting of saplings occurs in year 1 of the orchard life cycle, along with irrigation system installation, land preparation, fumigation, and a number of key management decisions like planting density and variety selection. Establishment (years 2-3) involves rapid tree growth and attendant biomass accumulation, a higher rate of tree loss 


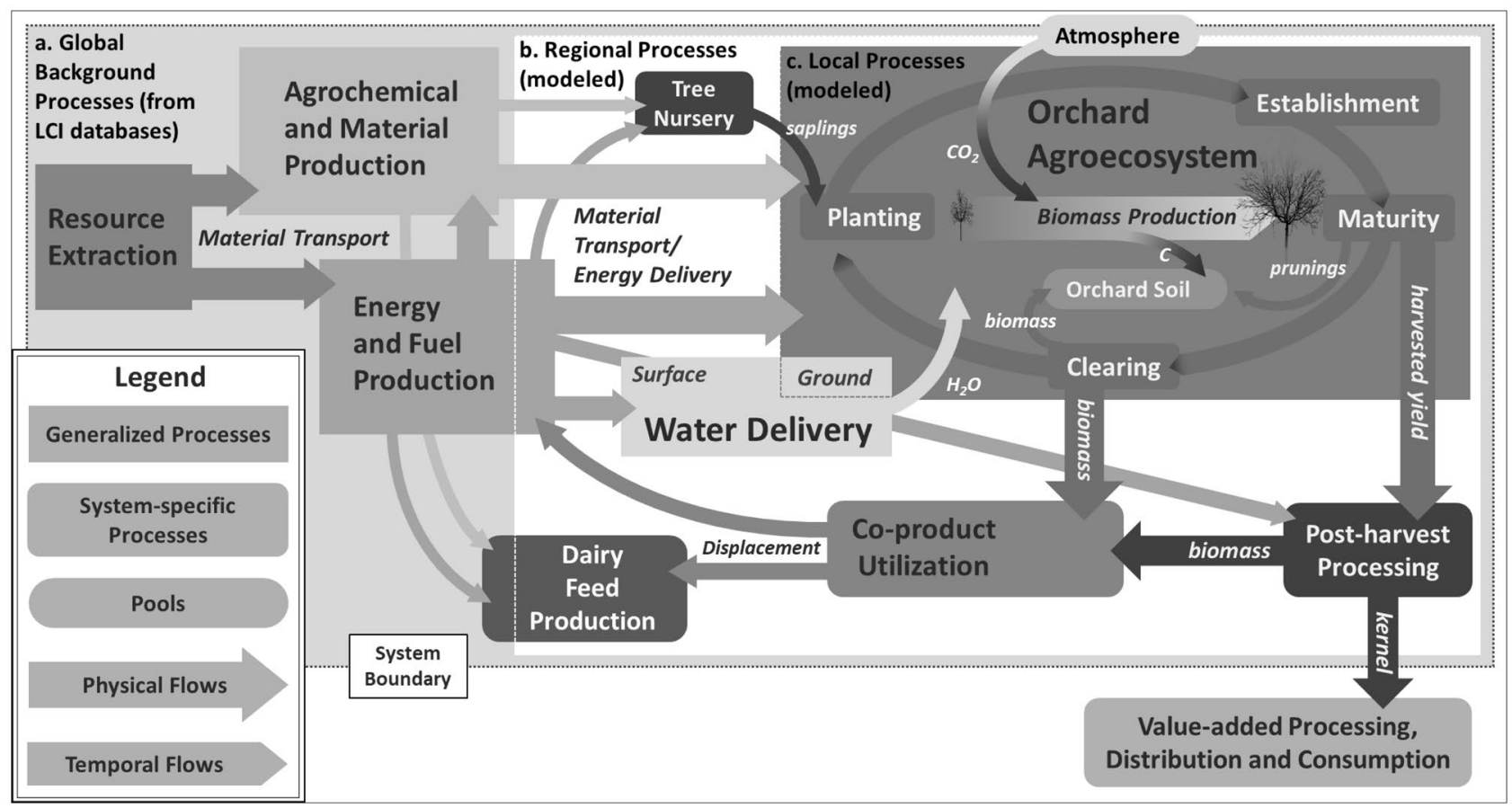

Fig. 1 System diagram. (a) Upstream processes, especially commodity production and transport, are assumed to occur on a global scale. These data are obtained from LCI databases via GaBi ts 6. (b-c) Processes occurring on regional (e.g., nursery production, surface water

and replacement, and structural pruning. Harvest and related operations (pollination, harvest, and postharvest) begin in year 3. Harvested almonds are comprised of a hull, shell, and kernel. Post-harvest operations thus yield almond kernel, along with hulls and shells.

The growth phase follows (years 4-7), during which biomass accumulation continues to increase logarithmically; agrochemical inputs increase in proportion to tree volume and nutrient demand. Maturity is reached at about year 8 , when biomass accumulation and yield pass the inflection point of the logarithmic growth curve, and orchard productivity and inputs reach a relatively steady state until orchard EoL, which is initiated when maintenance costs exceed income. The business-as-usual (BaU) scenarios for SV, SJV, and TL regions consider EoL to occur in years 21, 24, and 19 , respectively. EoL operations entail pushing and disposal of trees, either by in-field burning or chipping with subsequent delivery to bioenergy facilities, surface mulching, or soil incorporation of the chips. Assuming the orchard is replanted, the fallow year will begin anew (year 0 ).

$\mathrm{BaU}$ almond production for each region is based on regionally specific economic cost and return studies (Duncan et al. 2016; Pope et al. 2016; Yaghmour et al. 2016). These studies are based on consensus estimates of typical orchard inputs and management practices obtained from interviews and focus groups consisting of farm advisors, growers, and delivery, biomass energy generation, post-harvest operations) and local (e.g., orchard management, biomass accumulation, groundwater pumping) scales, including freight transport, are treated explicitly in the orchard LCA model

industry representatives. Additionally, the Almond Board of California (ABC) conducts grower self-assessment surveys through their California Almond Sustainability Program (CASP), which collects data on a few orchard inputs and a wide range of practices (ABC 2019).

Data on orchard planting parameters, agrochemical, fuel, water and material inputs, and orchard management operations (Table 1) from these sources were used to define $\mathrm{BaU}$ conditions, with the exception of orchard age at removal, which was obtained from analysis of historic aerial imagery (Google Earth Pro V. 7.3 2019). The BaU scenario is intended to represent a "typical" almond orchard in each of the three growing regions, as well as serving as a baseline for comparison with scenarios representing potential changes in management or environmental conditions. The results for each growing region are aggregated as an areaweighted mean to estimate results for the $\mathrm{CV}$ as a whole.

\subsubsection{Yield and biomass productivity}

Yield is modeled on an individual tree basis, using cost and return study estimates of typical regional yield, tree replacement rate, planting density (Figure $S 3$ of the supplementary material), orchard lifespan, and production costs. These data were coupled with county-specific almond prices (USDA NASS 2019) and tree loss rates obtained from analysis of 
Fig. 2 Hydrologic regions of California's Central Valley and extent of almond orchards. Growing regions and $\mathrm{CV}$ defined by hydrologic detailed analysis units from the California Department of Water Resources (California Natural Resources Agency 2019). Almond acreage obtained from USDA NASS CropScape Data Layer (USDA NASS 2019)

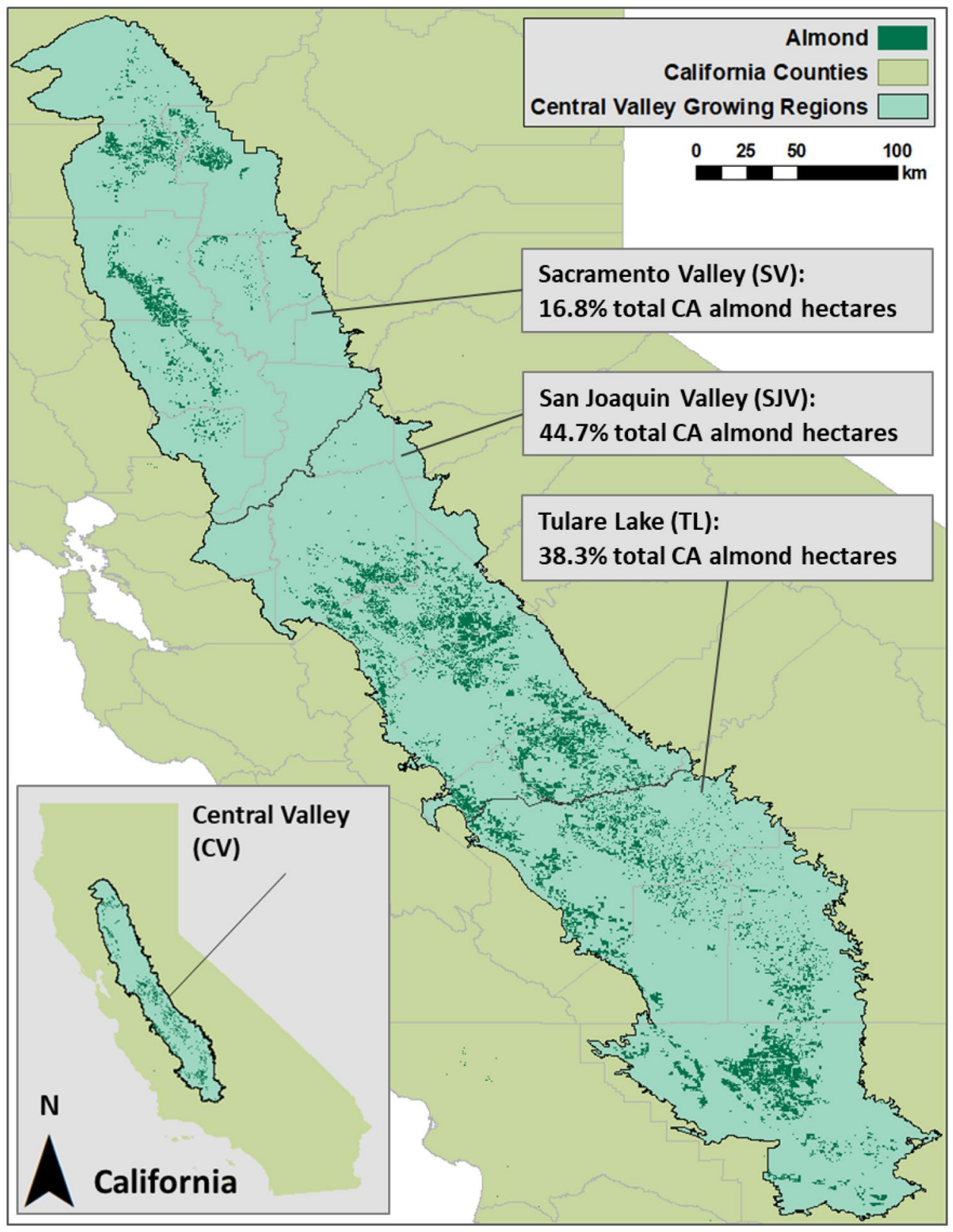

aerial imagery (Google Earth Pro V. 7.3 2019) to estimate individual tree lifetime productivity increase and decline, assuming that under typical circumstances a grower will remove the orchard once economic return no longer exceeds cost of production (Table 1). Under BaU conditions, therefore, the estimated kernel yield of the almond production system matches the regional cost and return study estimates with which the yield model was parameterized.

\subsection{Irrigation}

Regionally specific applied water quantities were taken from recent UC Cost Studies, making no assumption about effective rainfall, instead relying on grower and farm advisor estimates of actual applied water by region. These quantities should thus account for irrigation practice in both drought and normal years. Irrigation in California relies on an extensive surface water conveyance system and local groundwater. The location of use and the water supply type (surface versus groundwater) determine the energy intensity of irrigation water. No data on water supply type used in almonds at state, regional, or orchard scale are available. Instead, results from the Statewide Agricultural Productivity (SWAP) Model (Medellín-Azuara et al. 2011), an economic optimization model that uses water supplies and prices to simulate farmer decision-making, were used. The percentage of surface and groundwater 
Table 1 Regional orchard parameters and lifetime total inputs per hectare for $\mathrm{BaU}$ scenario

\begin{tabular}{|c|c|c|c|c|}
\hline Input & Unit & SV & SJV & $\mathrm{TL}$ \\
\hline Diesel & $\mathrm{kg} \mathrm{ha}^{-1}$ & $14,045.2$ & $17,171.1$ & $24,877.1$ \\
\hline Gasoline & $\mathrm{kg} \mathrm{ha}^{-1}$ & 812.0 & 828.1 & 773.7 \\
\hline Propane & $\mathrm{kg} \mathrm{ha}^{-1}$ & 84.0 & 90.4 & 116.1 \\
\hline Electricity & $\mathrm{MJ} \mathrm{ha}^{-1}$ & $110,155.6$ & $238,225.9$ & $455,300.1$ \\
\hline Solar electricity & $\mathrm{MJ} \mathrm{ha}^{-1}$ & $18,291.7$ & $46,756.0$ & $834,107.2$ \\
\hline Equipment and material transport & $\mathrm{kg} \mathrm{ha}^{-1}$ & $36,336.4$ & $36,801.4$ & $33,349.1$ \\
\hline Equipment and material transport & $\mathrm{km}$ & $1.27 \times 10^{8}$ & $1.27 \times 10^{8}$ & $1.17 \times 10^{8}$ \\
\hline Saplings & $\mathrm{kg} \mathrm{ha}^{-1}$ & 168.8 & 176.9 & 165.6 \\
\hline Pesticide (nursery) ${ }^{\mathrm{a}}$ & $\mathrm{kg} \mathrm{ha}^{-1}$ & 144.3 & 131.0 & 132.2 \\
\hline Fertilizer $\mathrm{N}$ (nursery) ${ }^{\mathrm{b}}$ & $\mathrm{kg} \mathrm{N} \mathrm{ha}^{-1}$ & 670.8 & 706.1 & 534.6 \\
\hline Fertilizer P (nursery) & $\mathrm{kg} \mathrm{P} \mathrm{ha}^{-1}$ & 6.3 & 6.6 & 5.0 \\
\hline Fertilizer K (nursery) & $\mathrm{kg} \mathrm{K} \mathrm{ha}^{-1}$ & 8.1 & 8.5 & 6.4 \\
\hline Poultry manure (nursery) & $\mathrm{kg} \mathrm{ha}^{-1}$ & 2913.1 & 3066.5 & 2321.5 \\
\hline Synthetic fertilizer total (nursery) & $\mathrm{kg} \mathrm{ha}^{-1}$ & 3702.8 & 3897.8 & 2950.9 \\
\hline Materials (planting) & $\mathrm{kg} \mathrm{ha}^{-1}$ & 16.1 & 16.6 & 15.8 \\
\hline Materials (irrigation) & $\mathrm{kg} \mathrm{ha}^{-1}$ & 942.5 & 878.7 & 1515.7 \\
\hline Water (irrigation) & $\mathrm{L} \mathrm{ha}^{-1}$ & $2.84 \times 10^{8}$ & $2.59 \times 10^{8}$ & $3.53 \times 10^{8}$ \\
\hline Fertilizer $\mathrm{N}$ (orchard) & $\mathrm{kg} \mathrm{N} \mathrm{ha}^{-1}$ & 3179.2 & 2837.6 & 3076.8 \\
\hline Fertilizer P (orchard) & $\mathrm{kg} \mathrm{P} \mathrm{ha}^{-1}$ & 4832.8 & 3404.8 & 4707.0 \\
\hline Fertilizer K (orchard) & $\mathrm{kg} \mathrm{K} \mathrm{ha}^{-1}$ & 370.4 & 34.2 & 364.4 \\
\hline Fertilizer total (orchard) & $\mathrm{kg} \mathrm{ha}^{-1}$ & $18,479.5$ & $16,956.2$ & $18,007.2$ \\
\hline Pesticide (orchard) & $\mathrm{kg} \mathrm{ha}^{-1}$ & 6926.4 & 963.0 & 6371.4 \\
\hline Hives (pollination) & Number ha ${ }^{-1}$ & 107.5 & 132.2 & 97.6 \\
\hline Planting density & trees ha ${ }^{-1}$ & 306.4 & 321.2 & 306.4 \\
\hline Observed mean age at removal & Years & 21 & 24 & 19 \\
\hline Kernel yield & Tons ha ${ }^{-1}$ & 48.1 & 49.7 & 52.1 \\
\hline Production cost & $\mathrm{USD} \mathrm{ha}^{-1}$ & 33,730 & 38,689 & 48,637 \\
\hline $\begin{array}{l}\text { Orchard floor nitrous oxide emission } \\
\text { factor (Deng and Salas 2017) }\end{array}$ & $\mathrm{kg} \mathrm{N}_{2} \mathrm{O} \mathrm{kg}{ }^{-1}$ applied $\mathrm{N}$ & 0.0057 & 0.0044 & 0.0031 \\
\hline
\end{tabular}

${ }^{a}$ Regional pesticide application rates are drawn from UC Davis economic cost and return studies on a per acre basis (Duncan et al. 2016; Pope et al. 2016; Yaghmour et al. 2016)

${ }^{\mathrm{b}}$ Includes poultry manure $\mathrm{N}$ used for irrigation by county calculated in SWAP was assigned to the orchard area in each county.

Once supply type is determined, the energy intensity of the supply in each county must be estimated. The impacts of irrigation water use are a function of total water demand and the energy intensity of water delivery. Groundwater pumping energy is a function of depth and was estimated using data from California Department of Water Resources test wells (California Natural Resources Agency 2019) for years 2012-2017 (including several years of drought conditions). In addition to water depth, groundwater pump technology and design affects energy demand. Technology-specific pump energy and efficiency data (Goulds Water Technology 2019) were used to generate a geospatial model estimating regional groundwater pumping energy demand across the CV (Figs. S4-S5 of the supplementary material).
Surface water energy intensity is a function of location in California; the extensive surface water delivery infrastructure in California includes large areas of gravity-fed water supplies, as well as areas where significant pumping energy is required. For surface water, aerial imagery (Google Earth Pro V. 7.3 2019) and spatial data from select irrigation districts in the CV were used to map surface water delivery infrastructure including the California Aqueduct and the Delta-Mendota Canal to almond orchards served.

In the state of California, there is increasing interest in the potential for groundwater recharge, whereby application of surface water can help maintain or increase groundwater levels, exceeding what would occur just with normal precipitation, a potential co-benefit of irrigation that can help sustain groundwater levels. Groundwater recharge potential was estimated based on spatial data (O'Geen et al. 2015; Kimmelshue et al. 2014), distribution of irrigation system types by county 
(Deng and Salas 2017), and irrigation system-specific water application efficiency values (UNFAO 1989). Groundwater recharge is assumed to occur incidentally during normal irrigation operations, with quantity determined by the water application efficiency of the local mix of irrigation system types obtained from California Almond Sustainability Program (CASP) data (ABC 2019).

\subsection{Almond co-products}

Almond orchards yield significant quantities of co-products at two stages: woody biomass generated at orchard EoL, and during post-harvest operations. While woody biomass and shells might arguably be designated by-products or waste in some locations because they have no value, or may even be a cost to farmers and operators to manage, all are referred to collectively as co-products. Table 2 summarizes the fates of these co-products in the SPARCS-LCA BaU cases.
Previous analyses (Kendall et al. 2015; Marvinney et al. 2015) assumed that a flat $95 \%$ of EoL biomass went to energy proportion based on data from an agriservices company active in the SJV region. The current analysis updates these estimates by developing a geospatial model that accounts for biomass energy facility closure and idling from 2014 to 2018, as well as ground-truthed orchard distributions and ages for each growing region (Kimmelshue et al. 2014).

These data were used as primary inputs to an R-based geospatial model that simulates the California orchard landscape over decadal timescales to predict the potential supply of energy feedstock derived from almond EoL biomass co-product (Table 2; Figs. S2, S6 of the supplementary information). This model also used the CropScape Data Layer (USDA NASS 2019) to simulate a competing supply of biomass energy feedstock from other perennial cropping systems in the $\mathrm{CV}$, as well as the logarithmic almond

Table 2 Co-product quantities and fates

\begin{tabular}{|c|c|c|c|c|c|c|c|}
\hline Region & Co-product & $\begin{array}{l}\text { Lifetime total } \\
\text { quantity }(\mathrm{kg} \\
\left.\text { ha }^{-1}\right)\end{array}$ & $\begin{array}{l}\text { Energy } \\
\text { feedstock } \\
(\%)\end{array}$ & $\begin{array}{l}\text { In-field } \\
\text { burning } \\
(\%)\end{array}$ & $\begin{array}{l}\text { Surface mulch/ } \\
\text { bedding }(\%)\end{array}$ & $\begin{array}{l}\text { Soil amend- } \\
\text { ment (WOR) } \\
(\%)\end{array}$ & Dairy deed (\%) \\
\hline \multirow[t]{7}{*}{ Sacramento Valley (SV) } & Orchard removal & 27,396 & 37 & 31.5 & 30 & 1.5 & 0 \\
\hline & Tree loss & 5506 & 0 & 50 & 50 & 0 & 0 \\
\hline & Prunings & 957 & 0 & 50 & 50 & 0 & 0 \\
\hline & Hulls & 29,681 & 0 & 0 & 25 & 0 & 75 \\
\hline & Shells & 8590 & 10 & 0 & 70 & 10 & 10 \\
\hline & Hash & 301 & 0 & 0 & 0 & 0 & 100 \\
\hline & Twigs & 498 & 10 & 0 & 70 & 10 & 10 \\
\hline \multirow[t]{7}{*}{ San Joaquin Valley (SJV) } & Orchard removal & 27,630 & 60 & 20 & 19 & 1 & 0 \\
\hline & Tree loss & 5425 & 0 & 10 & 90 & 0 & 0 \\
\hline & Prunings & 1109 & 0 & 10 & 90 & 0 & 0 \\
\hline & Hulls & 31,911 & 0 & 0 & 25 & 0 & 75 \\
\hline & Shells & 9235 & 10 & 0 & 70 & 10 & 10 \\
\hline & Hash & 323 & 0 & 0 & 0 & 0 & 100 \\
\hline & Twigs & 536 & 10 & 0 & 70 & 10 & 10 \\
\hline \multirow[t]{7}{*}{ Tulare Lake (TL) } & Orchard removal & 26,179 & 22 & 39 & 37 & 2 & 0 \\
\hline & Tree loss & 4660 & 0 & 10 & 90 & 0 & 0 \\
\hline & Prunings & 953 & 0 & 10 & 90 & 0 & 0 \\
\hline & Hulls & 29,647 & 0 & 0 & 25 & 0 & 75 \\
\hline & Shells & 8580 & 10 & 0 & 70 & 10 & 10 \\
\hline & Hash & 301 & 0 & 0 & 0 & 0 & 100 \\
\hline & Twigs & 498 & 10 & 0 & 70 & 10 & 10 \\
\hline \multirow{7}{*}{$\begin{array}{l}\text { Central Valley Area- } \\
\text { weighted mean }(\mathrm{CV})\end{array}$} & Orchard removal & 26,941 & 43.5 & 28 & 27 & 1.5 & 0 \\
\hline & Tree loss & 5095 & 0 & 16.4 & 83.6 & 0 & 0 \\
\hline & Prunings & 1015 & 0 & 16.4 & 83.6 & 0 & 0 \\
\hline & Hulls & 30,537 & 0 & 0 & 25 & 0 & 75 \\
\hline & Shells & 8838 & 10 & 0 & 70 & 10 & 10 \\
\hline & Hash & 310 & 0 & 0 & 0 & 0 & 100 \\
\hline & Twigs & 513 & 10 & 0 & 70 & 10 & 10 \\
\hline
\end{tabular}


growth model developed previously (Kendall et al. 2015) and spatial and operational data on biomass energy facilities (CARB 2019). The biomass energy feedstock landscape was simulated from years 2014 through 2020, and the estimated values for almond biomass to energy feedstock for year 2018 were used in this analysis.

Data on biomass-to-energy transport costs and payments for feedstock obtained from an agriservices company were used to generate facility-specific economically feasible transport radii (i.e., the distance within which the value of biomass feedstock does not exceed the cost of transport), allowing a regionally specific "feedstock-shed" based analysis of biomass delivery from almond orchard EoL operations to bioenergy facilities. This analysis treats the bioenergy facility as gatekeeper for potential fossil fuel substitution benefits attributed to the orchard production system, and accounts for facility-specific energy production capacity (and thus, feedstock demand) and competition for feedstock delivery from other perennial crops, municipal sources, and forestry by-products.

Biomass fate modeling assumes that the almond grower prioritizes between fates based on expense and feasibility (i.e., available capacity), with energy production being the most cost-effective, followed by in-field burning, surface mulching, and soil amendment or "whole orchard recycling" (WOR) (Holtz et al. 2014; Wolff and Guo 2019). Soil amendment may also be used to dispose of hulls, shells, and prunings in either tractor row soils during the orchard productive lifespan or off-site, whereas WOR, a relatively new possible practice, refers specifically to the incorporation of chipped EoL tree removals back into the floor soil of the orchard from which they were removed. Energy production is limited by the capacity of biomass energy facilities within the economically feasible transport radius of any given orchard block to accept additional biomass feedstock, and in-field burning is limited by air quality regulations. Once these pathways have reached their maximum, $99 \%$ of the additional biomass produced in that region is assumed to be directed to surface mulching, and $1 \%$ to WOR - a relatively new practice in California.

Post-harvest co-products are generated at hulling and shelling operations, where harvested in-hull almonds are transported. Data on post-harvest operations, inputs, and biomass co-products were obtained from a survey of hulling and shelling operations throughout the CV (Kendall et al. 2015). The primary co-products are hulls and shells, though hash (a mixture of crushed shells and kernel) and twigs are also generated, albeit in relatively small quantities. Almond hulls and hash are assumed to be used as a dairy feed, while shells and twigs tend to find lowervalue uses as livestock bedding or energy feedstock. Any of these co-products may also be incorporated into soils or surface mulched if not directed to another use. Table 2 describes the proportion of each co-product directed to each possible fate in each region.

For economic allocation, orchard EoL biomass is assigned a value of zero, because growers manage trees at a cost, rather than generating income. For post-harvest co-products, county-specific 5-year mean almond hull and kernel prices were obtained from the county crop commission reports for California, via the US Department of Agriculture (USDA) National Agricultural Statistics Service (NASS) database (USDA NASS 2019). The price of shell as bedding in 2019 was obtained from the UC Davis Animal Science Department and used in lieu of a mean commodity value. Hash and twig are included respectively within hull and shell production and price estimates, as specific commodity values for these co-products were not available (Table 3).

Using the substitution approach, orchard EoL biomass used as power plant feedstock (Table 2) are assumed to substitute for average electricity in the California grid mix. An average rather than marginal approach is used here because biomass power plants have long served baseload power functions on the California grid. The substitution calculation is conducted by taking the reference LCI for California electricity obtained from Gabi ts v6 (PE International 2019), minus the impacts of emissions from biomass combustion. For substitution calculations of postharvest co-products, almond hull is treated as a dairy cow feed input, similar in nutritional characteristics to alfalfa (Robinson 2015). Thus, alfalfa is assumed to be substituted by almond hulls. Data on the nutritional value of almond hash as a dairy feed was not available, so this co-product was treated identically to hulls.

Table 3 Co-product economic value

\begin{tabular}{|c|c|c|c|c|c|c|c|c|}
\hline Co-product & Data source & Temporal range & Unit & SV value & SJV value & TL value & $\begin{array}{l}\text { CV value (pro- } \\
\text { duction weighted) }\end{array}$ & $\begin{array}{l}\text { Allocation } \\
\text { (\% total value } \\
\text { at farm-gate) }\end{array}$ \\
\hline Kernel & CA Crop Commission & 2013-2017 & $\$ \mathrm{~kg}^{-1}$ & 5.59 & 6.19 & 5.93 & 5.99 & 0.972 \\
\hline Hull + hash & & 2013-2017 & $\$ \mathrm{~kg}^{-1}$ & 0.09 & 0.11 & 0.11 & 0.11 & 0.027 \\
\hline Shell + twig & UC Davis & 2019 & $\$ \mathrm{~kg}^{-1}$ & 0.02 & 0.02 & 0.02 & 0.02 & 0.002 \\
\hline
\end{tabular}




\subsection{Reference $\mathrm{LCl}$ datasets}

LCI data were obtained from ecoinvent v3.3 and Professional databases accessed via $\mathrm{GaBi}$ ts v6 (PE International 2019). We used a cutoff system model, the default provided by $\mathrm{GaBi}$ ts. The reference $\mathrm{LCI}$ datasets and their sources are described in Tables S1-S6 of the supplementary material. Where an exact match between a flow and reference LCI was not available, the most appropriate available substitute was used or a new LCI was generated. Where regionally specific LCI datasets were not available, LCI data for the same material or process from the most similar region available were used. Wherever possible, transformation process LCI datasets were used. Where the only available option for a particular input LCI was a market process dataset, explicit freight transport modeling was foregone in order to avoid double-counting transport flows.

A process-based LCI for almond pollination services was generated using the SPARCS-LCA model framework and data from an earlier study of GHG and air emissions of US honey production (Kendall et al. 2013), making use of updated LCI datasets (Table S2 of the supplementary information) accessible through $\mathrm{GaBi}$ ts. For quantification of avoided impacts due to displacement of dairy feed, a process-based LCI of alfalfa production in California was generated by parameterizing the SPARCS-LCA model framework with input and operation data (Table S3) obtained from UC Davis cost and return studies on alfalfa production (Clark et al. 2016; Long et al. 2015) and USDA Cropscape geospatial data (USDA NASS 2019). The full LCI datasets so produced are available as supplemental spreadsheets.

\subsection{Emission factors for combustion and soil emission}

Emission factors (EFs) for biomass combustion in bioenergy facilities were generated from data obtained from the CARB pollution mapping tool on annual emissions by facility (CARB 2019) and feedstock quantity. EFs for in-field burning of almond biomass (Table S7 of the supplementary information) were obtained from CARB air emissions reports (Jenkins et al. 1996). Soil nitrous oxide $\left(\mathrm{N}_{2} \mathrm{O}\right) \mathrm{EFs}$ sensitive to region, irrigation system, and fertilizer nitrogen source were obtained from an analysis that used the denitrification-decomposition (DNDC) model (Deng and Salas 2017), a geochemical process-based model, to assess GHG emissions and carbon storage in California's agricultural soils (Table 1). Biogenic $\mathrm{CO}_{2}$ emissions, such as those from biomass combustion and decomposition of soil organic matter, were treated as carbon neutral for purposes of Global Warming Potential calculation.

\subsection{Scenario and sensitivity analysis}

The influence of individual parameters on model results was quantified through sensitivity analysis in which model parameters relevant to biomass co-product fate and irrigation were varied systematically, with results expressed as percent change in model output vs percent change in parameter value. These two key processes were identified based on findings from an earlier LCA of California almonds showing that biomass co-product fate and irrigation were the most sensitive and influential processes in determining the impact of almonds (Marvinney et al. 2015). Parameter sensitivity values and response equations are recorded in Tables S8-S10 of the supplementary material associated with this article.

The effects of reduction in applied irrigation water on yield are modeled using data from recent research efforts establishing a water production function in California almond production (Goldhamer and Fereres 2017). No recent California-specific analysis for the effects of water application on biomass accumulation was available, so a biomass productivity function for almond was derived from analysis of irrigated almond production in Spain (Egea et al. 2010).

In addition to sensitivity analysis, potential orchard inputs and management practices are assessed using scenario analysis, to allow comparison of regional $\mathrm{BaU}$ practices with results for a hypothetical hectare of almond orchard under different management assumptions for EoL, annual, and postharvest biomass co-product fate (in-field burn, energy feedstock, surface mulch, or soil amendment), as well as irrigation system, pump, and water source. Scenarios affecting tree number or yield (e.g., planting density, replant rate, orchard EoL age, deficit irrigation) are assessed with explicit accounting for yield and biomass changes. The specific assumptions and model parameter changes used in each scenario are shown in Table S12 of the supplementary material.

\section{Results}

\subsection{Baseline ( $\mathrm{BaU})$ results}

Figures, 4, 5, and 6 show environmental impact results by region and operational category as well as co-product (Figs. 3 and 4) and LCA phase (Figs. 5 and 6), and reveal notable differences between the SV, SJV, and TL growing regions. Almond production in the SJV region performed best for most environmental impacts. Impacts attributable to brown skin almond kernel at postharvest facility gate as per economic allocation are $2.39(+0.33,-0.39) \mathrm{kg} \mathrm{CO}_{2}$ eq as $\mathrm{GWP}_{100}, 51.0(+8.4,-8.3) \mathrm{MJ}$ energy use, and $4820(+330$, 


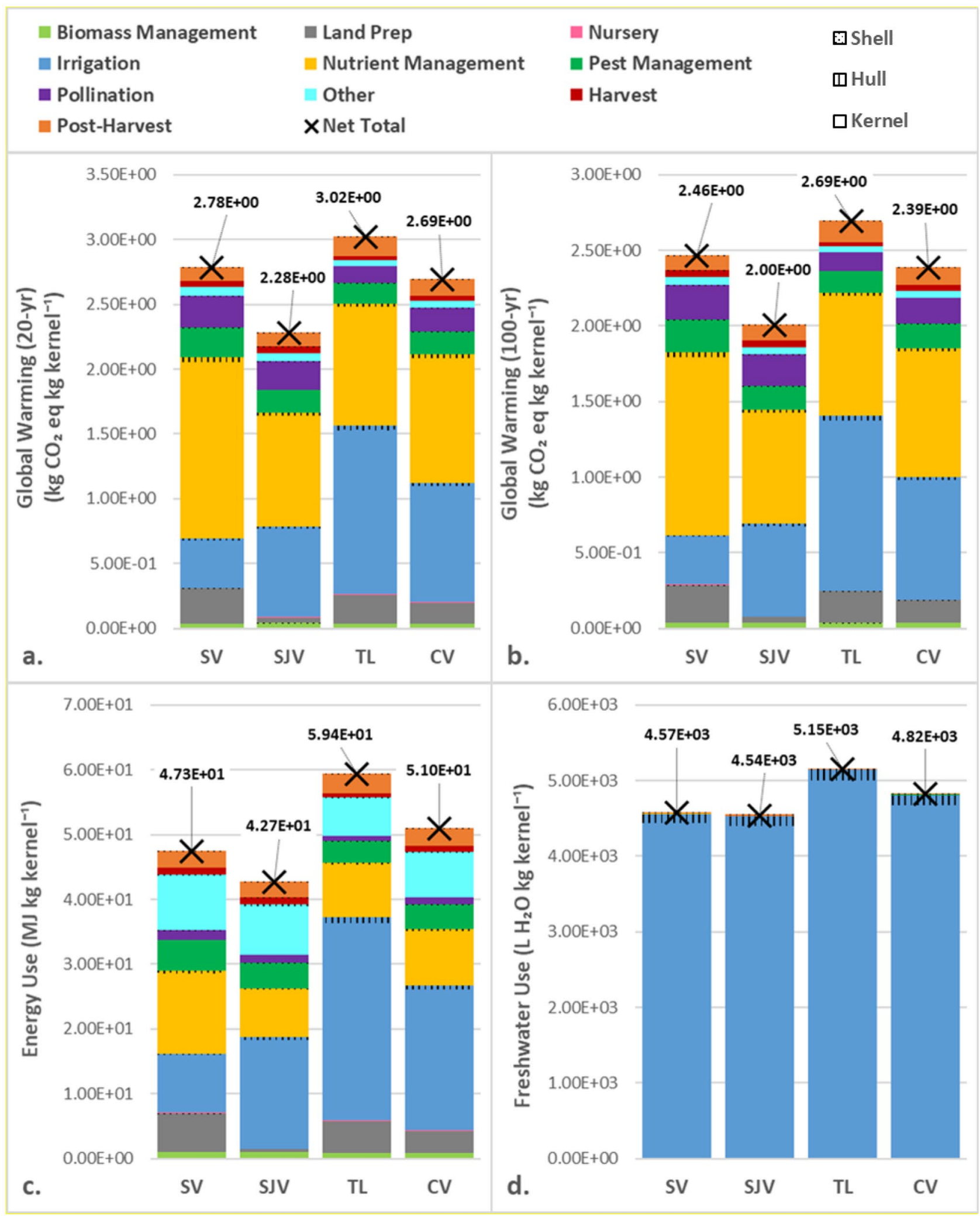

Fig. 3 Selected impact results using economic allocation, representative of 2012-2018 conditions, by region and aggregated to CV: a 20-year global warming, b 100-year global warming, $\mathbf{c}$ energy use, and $\mathbf{d}$ applied freshwater use (excluding rainfall) 


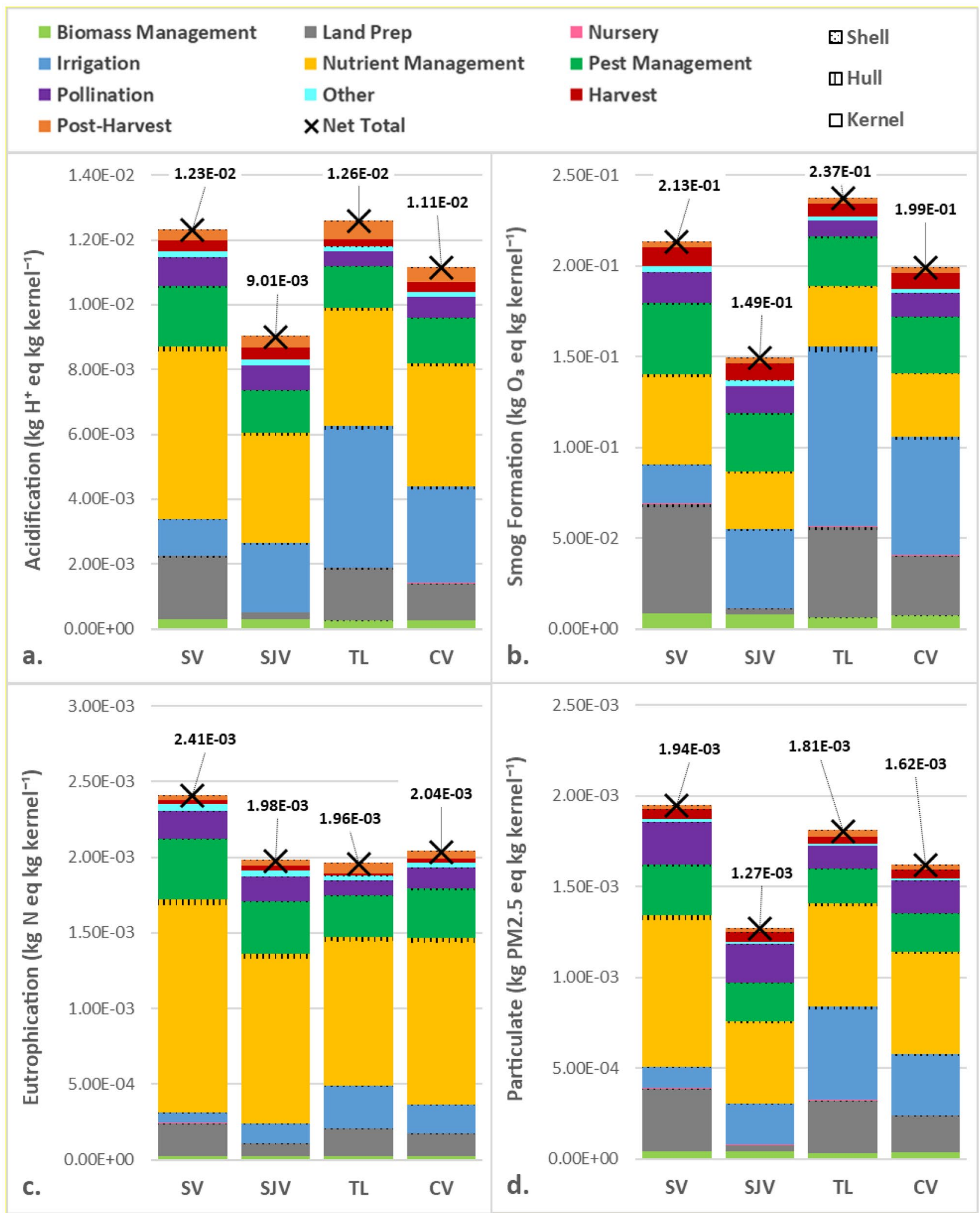

Fig. 4 Selected impact results using economic allocation, representative of 2012-2018 conditions, by region and aggregated to CV: a acidification, $\mathbf{b}$ smog formation, $\mathbf{c}$ eutrophication, and $\mathbf{d}$ particulate air emission 


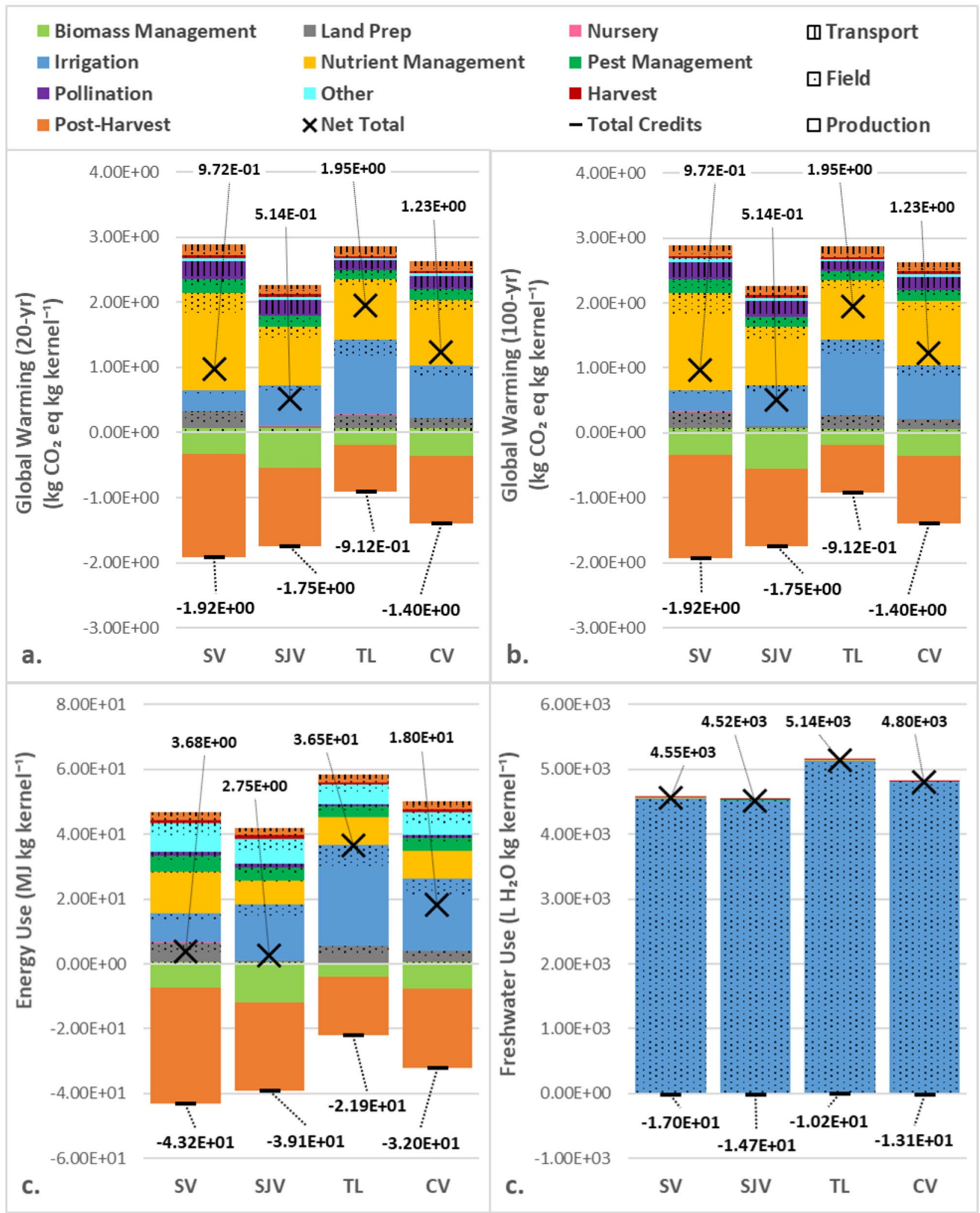

Fig. 5 Selected impact results using a substation approach for allocation, representative of 2012-2018 conditions, by region and aggregated to CV: a 20-year global warming, b 100 year global warming, c energy use, and $\mathbf{d}$ applied freshwater use (excluding rainfall). Production, Transport, and Field refer to LCA phases treating upstream, transportation, and on-site processes respectively 


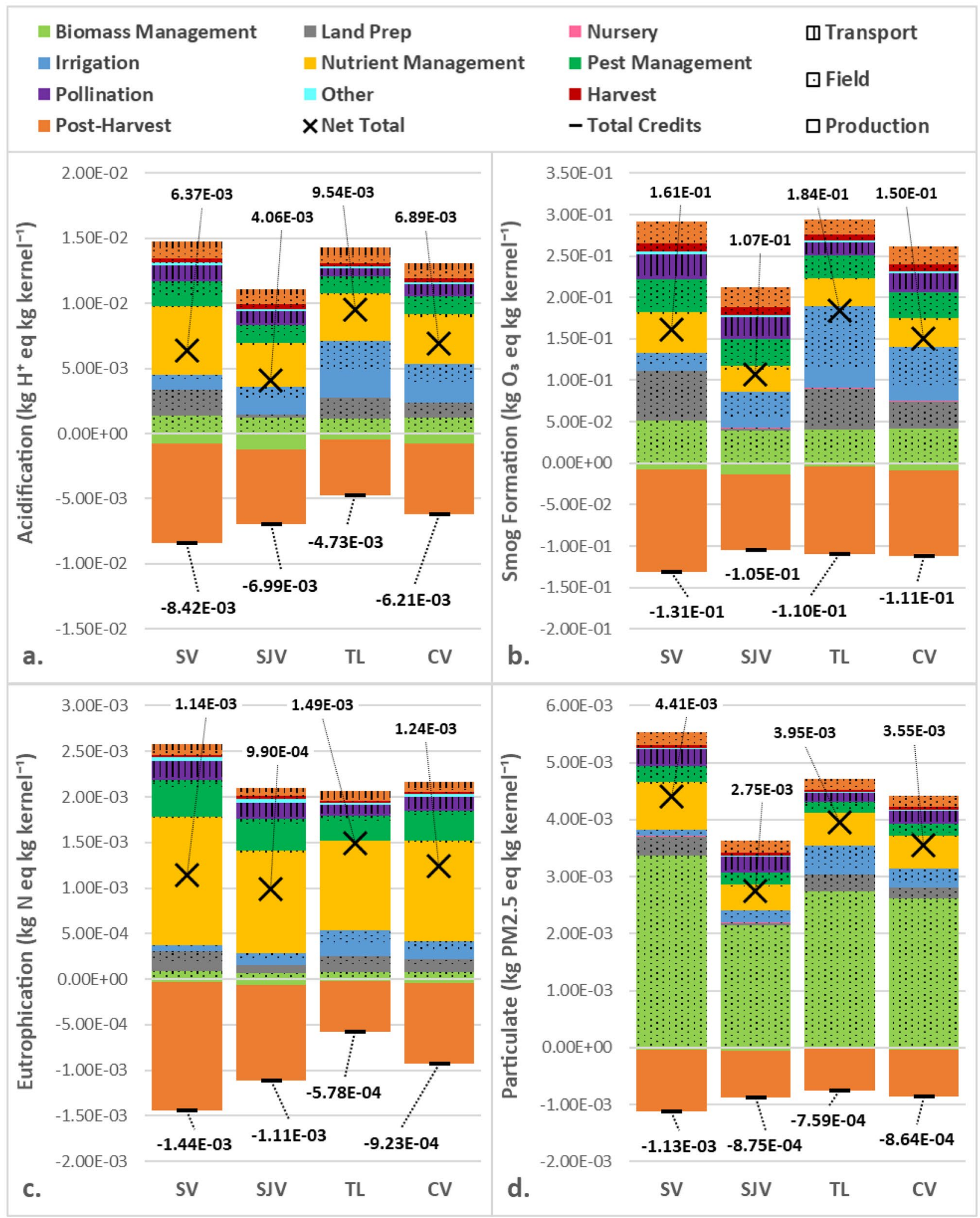

Fig. 6 Selected impact results using a substitution approach for allocation, representative of 2012-2018 conditions, by region and aggregated to CV. a Acidification, $\mathbf{b}$ smog formation, $\mathbf{c}$ eutrophication, and d particulate air emission. Production, Transport, and Field refer to LCA phases treating upstream, transportation, and on-site processes respectively 
-280) L freshwater use (Fig. 3), expressed as Central Valley area-weighted mean plus and minus regional variation.

Expressed as area-weighted CV mean and regional value range, $1 \mathrm{~kg}$ of brown skin almond kernel at postharvest facility gate under typical ( $\mathrm{BaU})$ conditions is responsible for 1.23 ( \pm 0.72$) \mathrm{kg} \mathrm{CO}_{2} \mathrm{eq}\left(\right.$ as $\left.\mathrm{GWP}_{100}\right), 18.1$ (+18.4, -14.4) MJ energy use, and $4804(+334,-283 \mathrm{~L})$ freshwater use. These values include co-product credits (based on substitution) of $1.40(+0.5,-0.49) \mathrm{kg} \mathrm{CO}$ eq (as $\left.\mathrm{GWP}_{100}\right), 32.0$ $(+11.2,-10.1)$ MJ energy, and $13.1(+3.9,-2.9) \mathrm{L}$ freshwater. The decrease in impact values demonstrated here is due to the significant resource use and emission credits attributable to the almond production system when using substitution (Figs. 5 and 6) and which are not reflected in the economic allocation approach. Results for additional impact categories are presented in Table S11 of the supplementary material. Some of these regional differences can be explained by differences in soil nitrous oxide emissions rates from fertilizer application (Deng and Salas 2017).

Interpretation of results for many impact categories is challenging, due to the lack of geographic specificity in the reference LCIs, a common challenge for LCA. For example, unlike for many agricultural crops in the USA, almond cultivation in California has very low direct emissions (e.g., leaching) that cause eutrophication of proximal waterbodies. Instead, eutrophication is caused by emissions to air and water throughout the supply chains that support almond production, and through deposition of nitrogenous air emissions at the cultivation and handling sites that cause eutrophication elsewhere.

\subsection{Sensitivity and scenario analysis}

We used sensitivity analysis to determine the parameters most influential over model outputs in various impact categories (Figs. 7, 8, and 9). We find that orchard planting density (trees ha ${ }^{-1}$ ), which affects total yield calculation, and per-tree material and chemical inputs, applied water, and kernel yield are the most important parameters in determining most impacts when using kilogram of kernel as the functional unit. Irrigation water use efficiency and surface water use are also significant, especially for freshwater use and water scarcity impacts. Most model parameters tested produce nonlinear responses due to interactions between model components and nonlinear relationships between orchard age and agronomic factors
Fig. 7 Selected global warming potential (100-year) sensitivity analysis results, cutoff at $0.01 \%$. *Nonlinear response

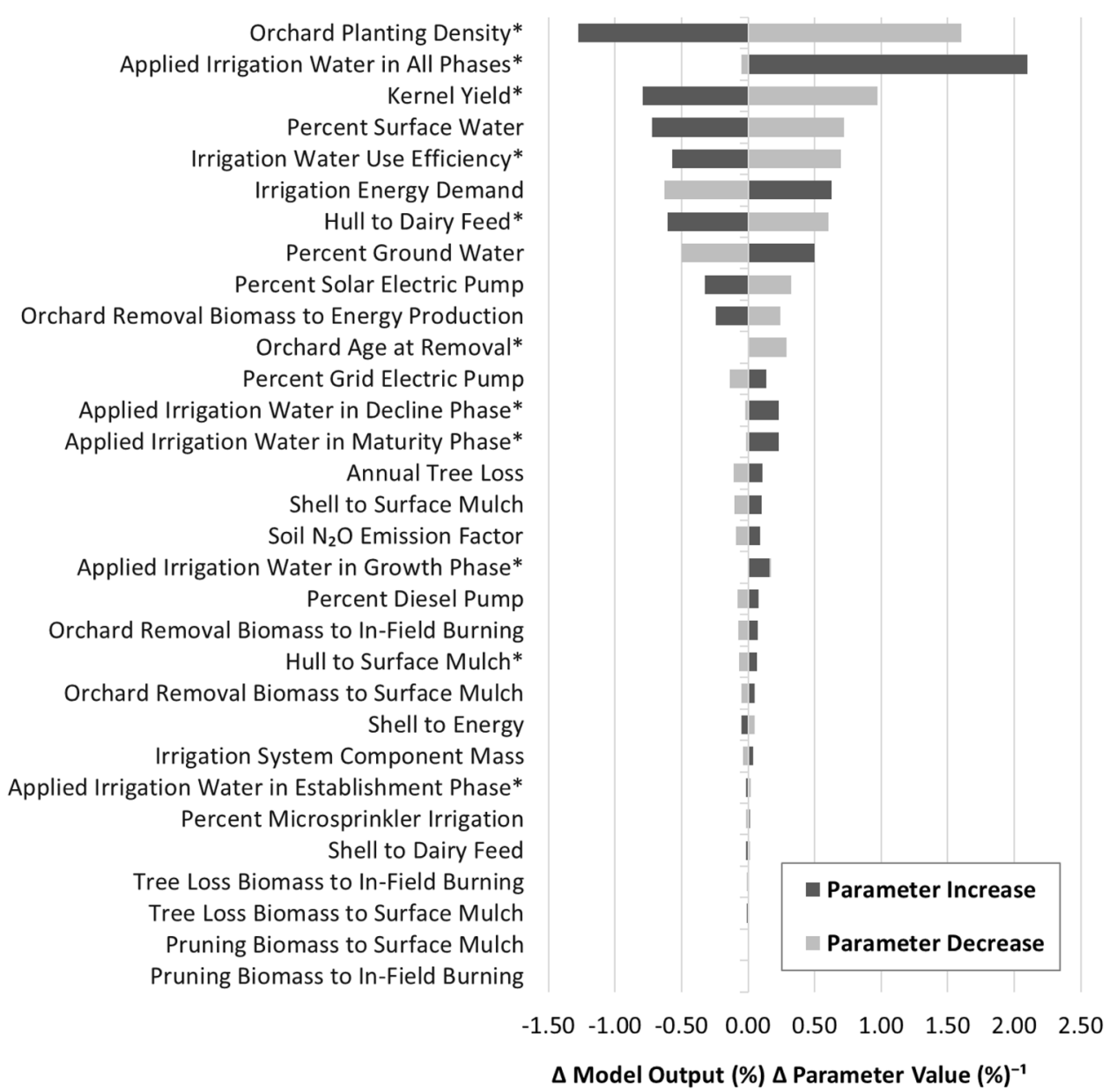

$\Delta$ Model Output (\%) $\Delta$ Parameter Value $(\%)^{-1}$ 
Fig. 8 Selected energy use sensitivity analysis results, cutoff at $0.01 \%$ (*indicates nonlinear response)

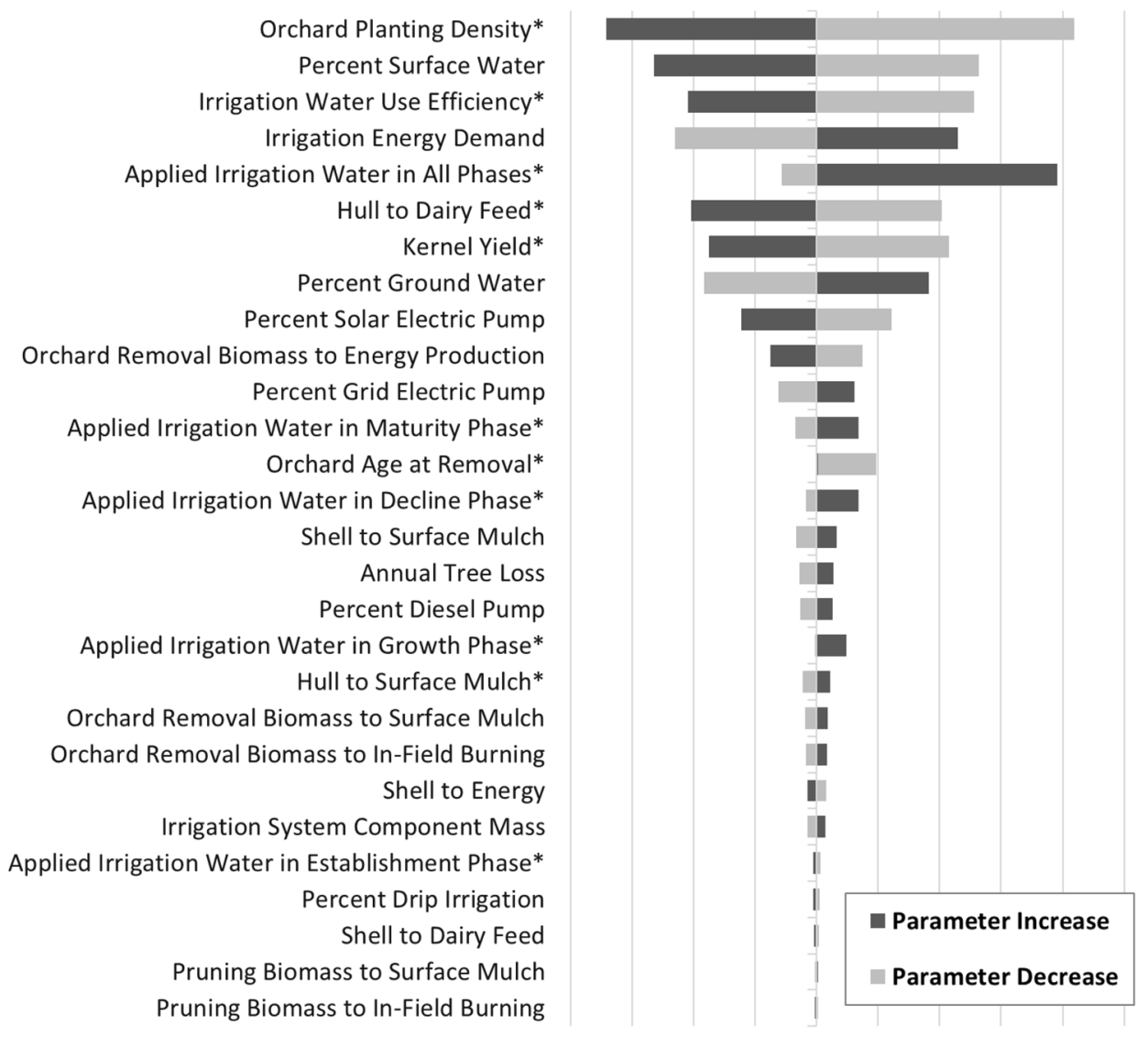

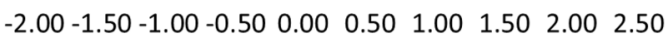

$\Delta$ Model Output (\%) $\Delta$ Parameter Value $(\%)^{-1}$ such as biomass accumulation, yield production, and water demand. For some parameters, this results in model sensitivity outputs in which the model response depicted in tornado chart format (Figs. 7, 8, and 9) appears to increase or decrease regardless of whether the parameter being tested increases or decreases. Model sensitivity to these parameters is examined in greater detail in the supplementary material Figs. S8-S10 of the supplementary material. Sensitivity analysis uses the substitution method for coproduct allocation.

We used scenario analysis to explore various potential orchard management and modeling alternatives, and to highlight potential tradeoffs in environmental performance arising from changing production practices. Scenario analysis uses the substitution method for co-product allocation. Figures 10 and 11 show biomass utilization and irrigationrelated scenario results, respectively, normalized relative to the BaU scenario. Disposal of woody biomass by-products (prunings and tree removal) through in-field burning resulted in a more than a fourfold increase in particulate (PM2.5eq) emissions and more than doubled smog formation potential, whereas maximum utilization of biomass for electricity generation resulted in close to a $50 \%$ reduction in life-cycle particulate and GHG emissions and almost a $100 \%$ reduction in energy use due to bioenergy production.

Surface mulching and WOR scenarios outperformed the in-field burn scenario in GHG emission, particulate emissions, and smog formation but resulted in slightly higher energy and fossil fuel demand (Fig. 10a), due to reduced fossil-fuel use in the burn scenario and avoided fossil fuel credits in the biomass to energy scenario. The biomass to energy scenario outperformed the other scenarios in every impact measurement except particulate emission. Postharvest co-product, yield, and 2018 age-weighted scenarios (as described in Table S12 of the supplementary material) resulted in less extreme variation from the BaU scenario, while changes to dairy feed displacement options produced the greatest variability-especially in fossil fuel and energy use (Fig. 10b). Of these scenarios, eliminating dairy feed displacement credits resulted in the highest impacts.

Irrigation pumping scenarios produced a wider range of results, with reliance on diesel pumping resulting in increased GHG emission and energy use of about $150 \%$, and smog formation potential of almost $300 \%$. Solar pumping and use of a cost-optimized pumping model (Fig. S4 of the supplementary material) result in the lowest impacts, and a net negative value 
Fig. 9 Selected freshwater use sensitivity analysis results, cutoff at $0.01 \%$ (indicates nonlinear response)

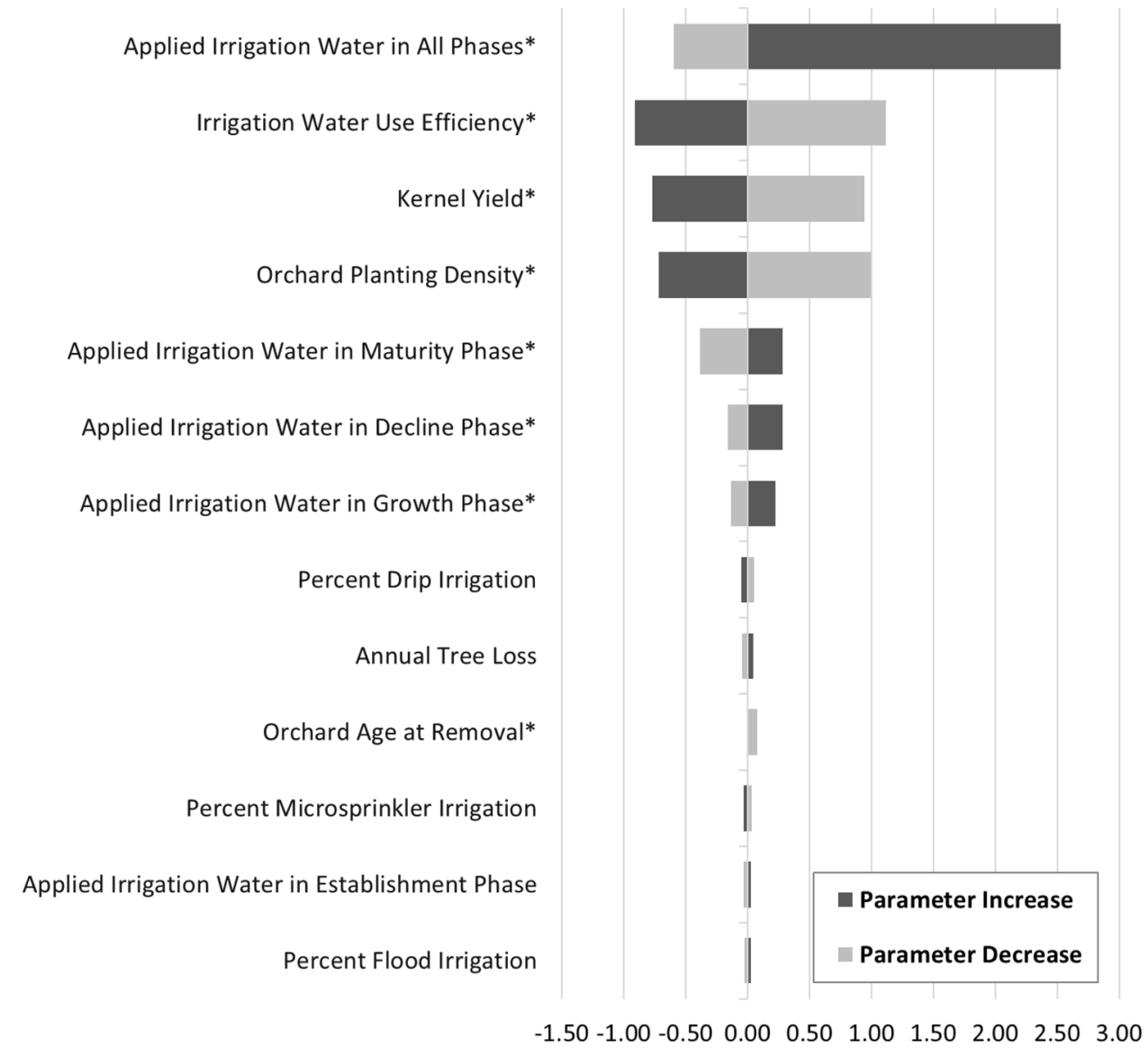

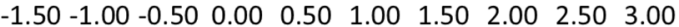

for energy demand - again accounting for bioenergy production credits (Fig. 10a). Surface water use produced the best overall environmental performance, reducing GHG emissions by almost $50 \%$, and energy use by almost $100 \%$ compared to $\mathrm{BaU}$, while exclusive reliance on groundwater produced the highest impacts. In general, use of different irrigation systems (microsprinkler, sprinkler, drip, flood) had minimal effects, with the exception of an approximately $20 \%$ increase in water use and scarcity impacts for flood irrigation, due to lower water use efficiency (Fig. 11b).

\subsection{Comparison with previous analysis}

This analysis has produced notable differences from previously published results, particularly in the areas of nutrient management, irrigation, biomass management, and pollination. This is due in part to more comprehensive modeling in the current analysis, but also due to changes in the California almond production landscape itself-especially in terms of irrigation water source and biomass energy production for the time frames analyzed. Overall, we find that the GHG intensity of almond production on a per $\mathrm{kg}$ kernel basis has increased by $0.30 \mathrm{~kg} \mathrm{CO}_{2} \mathrm{eq} \mathrm{kg}^{-1}$ kernel compared with results produced in 2015 , driven mainly by increases of $0.18 \mathrm{~kg} \mathrm{CO}_{2}$ eq from nutrient management, $0.11 \mathrm{~kg}$
$\mathrm{CO}_{2}$ eq from pollination, and $0.42 \mathrm{~kg} \mathrm{CO}_{2}$ eq from irrigation (Fig. 12a). Changes in estimated impacts from pollination are the result of using a more comprehensive LCI than that used in the 2015 almond LCA. While both studies relied on a previous US honey carbon footprint (Kendall et al. 2013), the new pollination LCI was developed specifically for this project with updated reference LCIs and activity-based allocation as described in Section $\mathrm{S} 2$ and Table $\mathrm{S} 2$ of the supplementary information.

Energy use impacts have decreased by $7.78 \mathrm{MJ} \mathrm{kg}^{-1} \mathrm{ker}-$ nel, driven mainly by an increase in post-harvest credits from displacement of alfalfa used in dairy feed (Fig. 12b). In the 2015 study, post-harvest and EoL biomass co-product utilization credits were aggregated in reporting. In this analysis, we separate the two sources of credits from displacement of fossil fuel-intensive processes. Bioenergy production from EoL biomass has decreased in California since then with plant closures, but despite this the electricity grid has decarbonized significantly in this timeframe, resulting in reduced value for displacement of fossil fuels in electricity generation. This loss of credits has been offset by increased use of almond hulls as dairy feed (Table 2) as well as increased value of displacement due to the findings of LCA of regional alfalfa production as described in Section S2 and Table S3 of the supplementary material. 
Fig. 10 Selected co-productrelated scenario analysis results aggregated by acreage to the $\mathrm{CV}$, normalized to $\mathrm{BaU}$ results. a Biomass co- and by-product fates: maximum quantities to bioenergy feedstock, in-field burn, surface mulch, and whole orchard recycling (WOR). b Post-harvest treatment: results at farm-gate (no post-harvest), no substitution of alfalfa production from hull co-product as dairy livestock feed, Cost Study (rather than explicitly modeled) yield estimate, and a snapshot of 2018 production using temporal and spatially resolved data

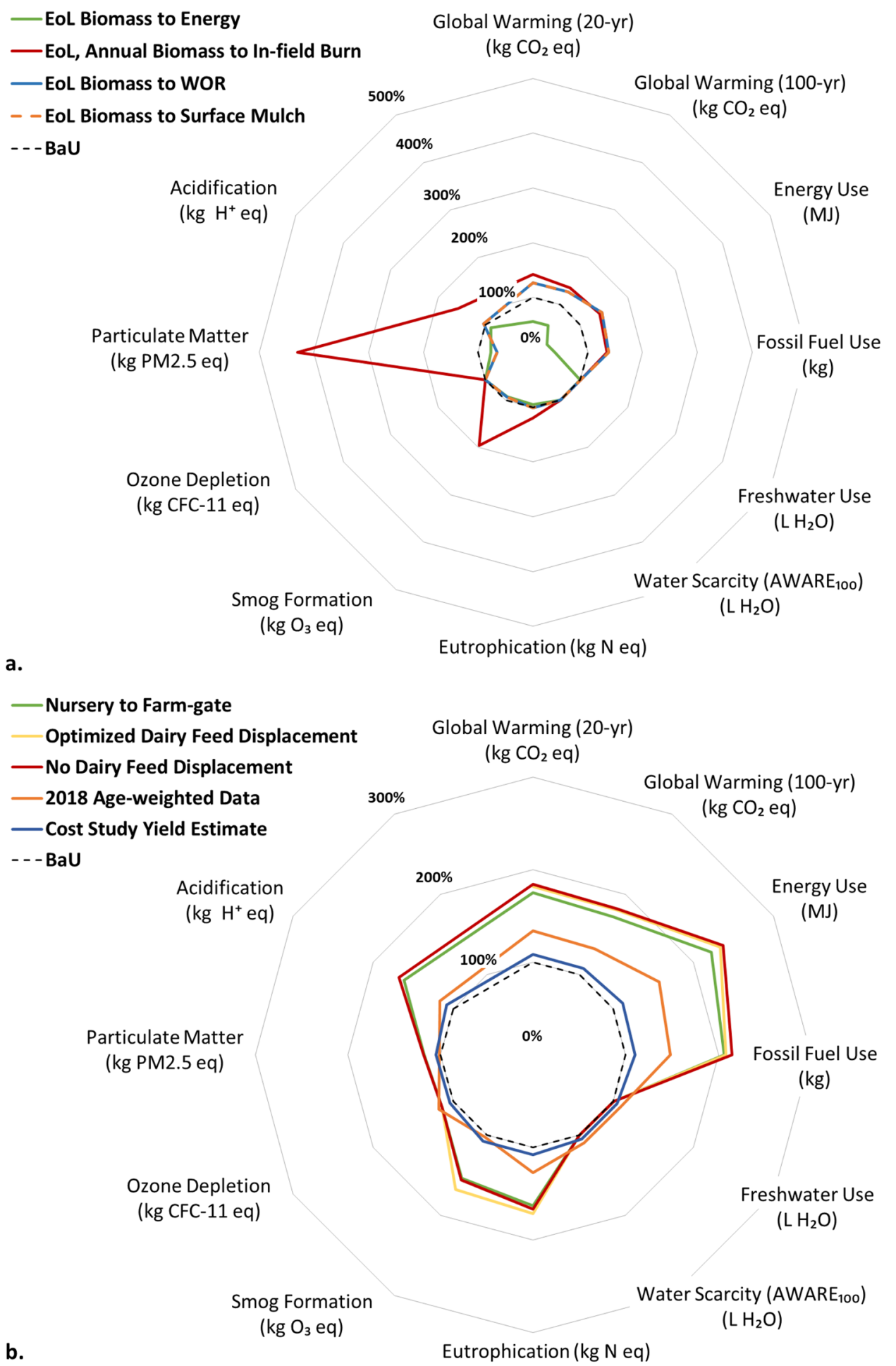

\section{Discussion}

\subsection{Drought and water}

California's recent multi-year drought (2011-2017) has had significant impacts on the regional almond industry. Under drought conditions, snowpack water storage in the Sierra
Nevada is reduced, resulting in curtailed surface water delivery in the CV (Hyles 2017). Perennial crops generally require water input throughout their lifespan (i.e., perennial crop water demand is inelastic in the sense that they cannot simply be left fallow during years of lower water availability during the growing season), and so the lack of surface water must be compensated for through increased 
Fig. 11 Selected irrigationrelated scenario analysis results aggregated by acreage to the $\mathrm{CV}$, normalized to $\mathrm{BaU}$ results. a Irrigation water delivery modeling options and pump type: cost optimized model, linear model; diesel pump, grid electric pump, and solar electric pump. b Water source and irrigation system: surface water, groundwater; drip, microsprinkler, solid set sprinkler, and flood/furrow

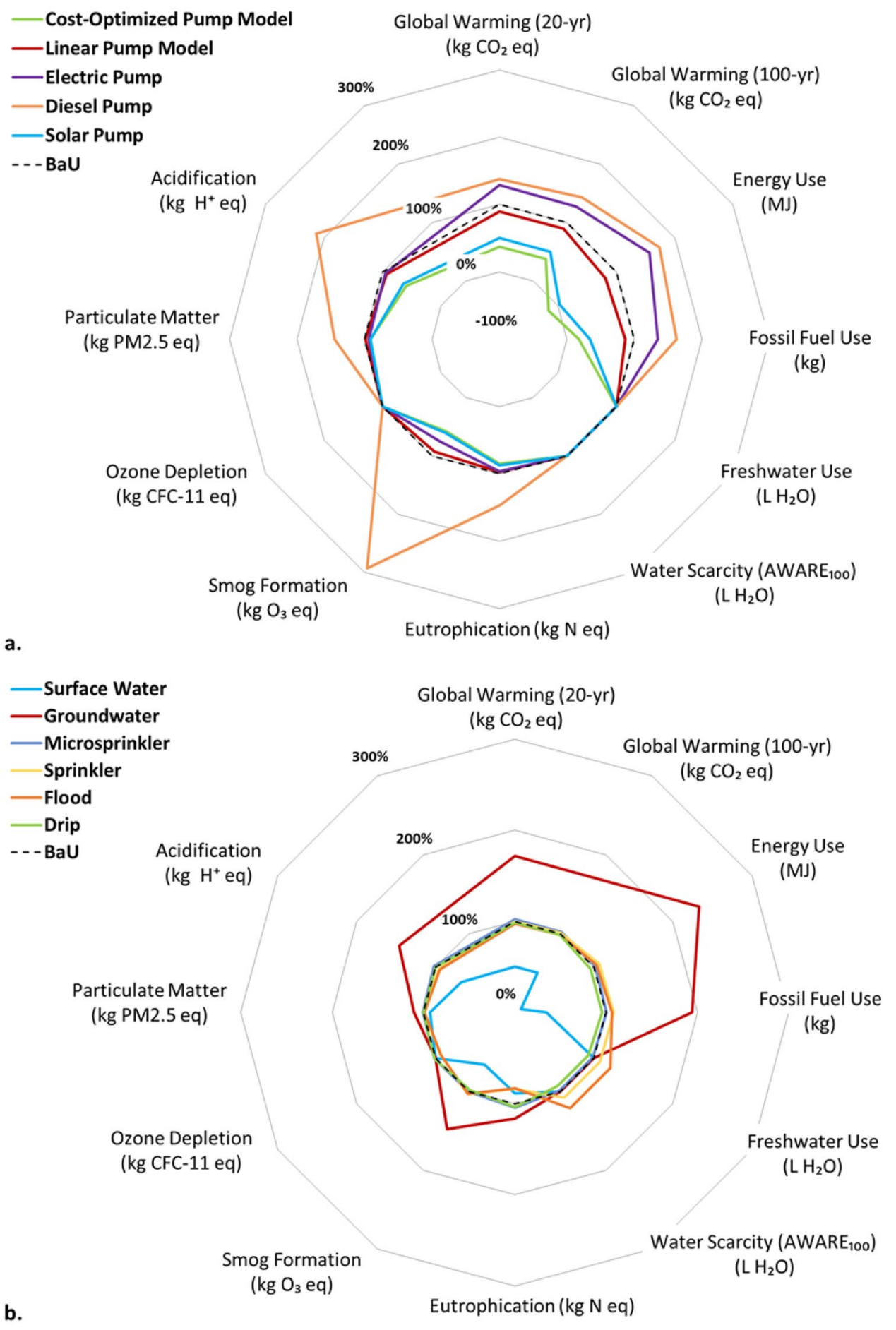

use of groundwater sources, leading to depletion of aquifers, increased groundwater depth, and a corresponding increase in energy demand for groundwater extraction (Hyles 2017) (Figs. S4-S5 of the supplementary material).

$\mathrm{BaU}$ scenario results (Fig. 5d) indicate that irrigation is the primary driver of freshwater consumption, with upstream freshwater use in input manufacturing and transport negligible compared to quantities applied in-field.
Irrigation was also a primary driver for energy consumption $(61.6 \%)$, and a major contributor to global warming impacts $\left(27.3 \%\right.$ for $\left.\mathrm{GWP}_{100}\right)$, largely due to the carbon intensity of the California electricity grid and reliance on electric and diesel pumps. Irrigation was less important to other environmental impacts (Fig. 6). This level of freshwater consumption (4555 to $5140 \mathrm{~L}$ per kg kernel) is comparable with global mean almond production water 
Fig. 12 Comparison of $\mathrm{CV}$ BaU. a GHG emission and b energy use results between previous (Kendall et al. 2015) and current analyses. Credits from post-harvest biomass co-product utilization are included in removal credits in 2015 analysis, but calculated separately in current (2019) analysis

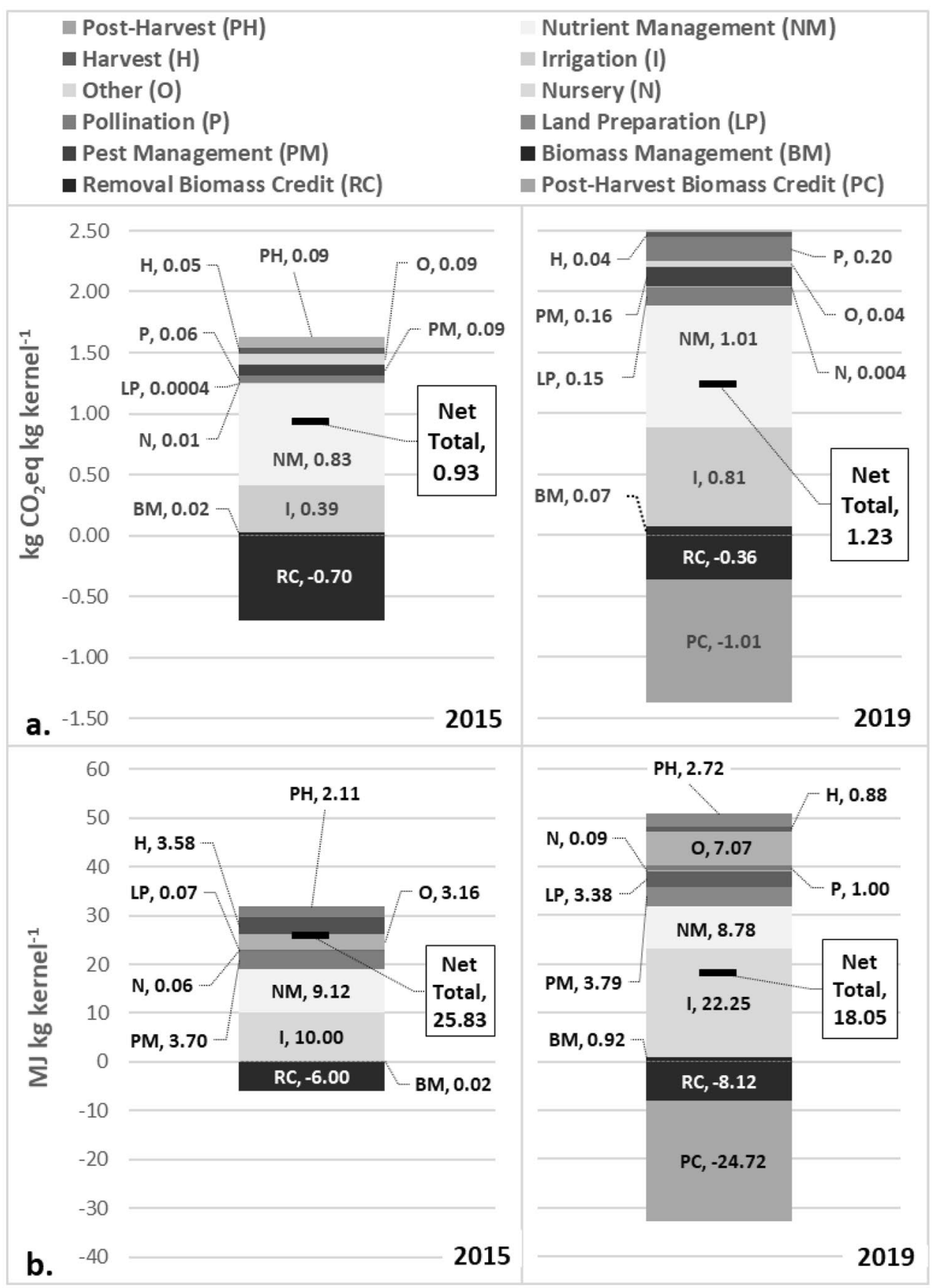

footprints (Mekonnen and Hoekstra 2011), as well as water footprints for a number of other high-protein tree crops and agricultural commodities (Fig. S9 of the Supplementary material). The freshwater use impact estimated here largely corresponds to the blue water component of water footprint analysis and agrees reasonably well with recent findings on the water footprint of California almond production (Fulton et al. 2019). This analysis also explored the possibility of incidental groundwater recharge as a function of orchard water use efficiency (UNFAO 1989) and soil suitability (O'Geen et al. 2015). Groundwater recharge quantity was estimated at about $0.1 \%$ of water use on a per kilogram of yield basis (Fig. 6d), and as such is not an important contributor to overall net life cycle water use.

Sensitivity analysis (Figs. 7, 8, and 9) demonstrates the importance of irrigation parameters to overall model outcomes, not just in terms of freshwater consumption but also energy use and other environmental impacts. The following tested parameters were demonstrated to produce changes in model output greater than the cutoff value of $0.01 \%$ : applied irrigation water, irrigation water source 
(surface or ground), water use efficiency, pump type (grid electric, diesel, or solar electric), and irrigation system (drip, microsprinkler, sprinkler, or flood). We found that applied irrigation water quantity was a major driver of freshwater consumption (Fig. 9).

This parameter was also an important driver of the other environmental impact categories examined, particularly GHG emissions (Fig. 7). The effects of irrigation application rate on GHG emissions are driven by both energy use for water delivery and the agronomic response of the almond tree to irrigation, as defined by the water-productivity relationships elucidated for yield (Goldhamer and Fereres 2017) and biomass accumulation (Egea et al. 2010). That is, reduced irrigation results in reduced growth and yield, which in turn increases the per-kernel impacts from inputs and processes that remain constant with the baseline assumption that water application is optimized for maximum yield under typical circumstances. The combined effects of changing energy demand and changing biomass productivity result in a nonlinear relationship between application rate and various environmental impact outputs, particularly global warming (Fig. 7).

Scenario analysis (Fig. 11) showed that the use of surface water for irrigation reduced all categories of environmental impact compared to the BaU scenario, whereas use of groundwater increased them, as observed in (Marvinney et al. 2015). However, the magnitude of the difference in impacts between surface and groundwater-fed orchards was greater in the current analysis, due largely to increased groundwater depth and sophistication of pump energy use modeling (Figs. S4-S5 of the supplementary material). Grid electric-powered irrigation pumping increased all impact categories over the $\mathrm{BaU}$ scenario. Diesel-powered irrigation pumping resulted in higher impacts overall, especially acidification and smog formation (driven by air emissions of $\mathrm{NO}_{x}$ and other nitrogenous compounds), while solar pumping performed best across all impact categories. Drip and microsprinkler irrigation scenarios resulted in slightly reduced impacts across all categories, while solid-set sprinkler and flood irrigation scenarios slightly increased impacts, due largely to increased water use efficiency in microirrigation and corresponding reductions in water and energy demand.

\subsection{Biomass fate and bioenergy infrastructure}

Since 2015, a significant proportion of California's biomass power plants have closed or been idled, resulting in drastic changes to the bioenergy infrastructure landscape that has historically provided a pipeline for utilization of orchard EoL biomass. Modeling of these changes (Fig. S6 of the supplementary material) shows that previous (Kendall et al. 2015) estimates of almond biomass utilization for energy production are no longer valid, with bioenergy plants able to accept no more than $22-60 \%$ of almond EoL biomass in 2018 (Table 1; Fig. S6 of the Supplementary material).

These infrastructure changes have had marked effects on GHG and other environmental impacts of almond production. The severe reduction of EoL biomass-to-energy feedstock utilization in the SV and TL regions has contributed to higher per kernel impacts, especially GHG emissions (Fig. 5a, b), smog formation potential, and particulate health impacts (Fig. 6c, d). This is due both to the lost opportunity for displacement of emission-intensive fossil fuel combustion and to a corresponding increase in in-field burning of EoL and annual biomass co-products-a major source of GHG $\left(\mathrm{CH}_{4}\right.$ and $\mathrm{N}_{2} \mathrm{O}$ in particular, given that biogenic $\mathrm{CO}_{2}$ is treated as carbon neutral in this analysis), particulate, and pollutant emissions (Jenkins et al. 1996).

Smog formation and particulate impacts are particularly important in the SJV, due to ongoing difficulties in meeting federal air quality standards and their disproportionate impacts on socioeconomically disadvantaged communities. Scenario analysis demonstrates that switching from bioenergy feedstock to surface mulching or WOR for EoL biomass disposal—rather than in-field burning—is a good option for growers to reduce particulate emissions and smog formation on a local and regional basis (Fig. 10a). These management alternatives even outperform bioenergy in these impact categories, despite the fossil fuel substitution credits attributed to the system in this scenario.

The tradeoff for adoption of surface mulch or WOR, however, is an increase in GHG emission as measured by $\mathrm{CO}_{2}$ eq over the $\mathrm{BaU}$ baseline (which includes significant GHG credits from bioenergy use that are lost with alternative biomass disposal practices)—only slightly less than the $\mathrm{CO}_{2}$ eq emissions from in-field burning, due to the greater quantity of fossil fuels combusted for on-site chipping, spreading, and tillage operations. However, the GWP method for assessing global warming cannot capture the benefits of temporary (less than 100 years) carbon storage, which can be significantly increased by WOR. However, woody biomass addition to soils may cause reduced nitrogen availability, potentially affecting yield and productivity. Although ongoing analysis of WOR in the California almond context indicates that these effects are limited to the first 2-3 years of the orchard lifespan (Holtz et al. 2014), future work is planned to better understand the effect of this practice on long-term carbon storage (e.g., greater than 100 years) in soils and in standing biomass in the second generation orchard, as well as to account for temporary carbon storage using a time-adjusted warming potential metric (Kendall 2012). 


\subsection{Conclusion}

This analysis reveals a number of potential tradeoffs between different impacts for various management options in the CA almond production landscape (Figs. 10 and 11). For example, increased GHG emissions are traded for reduced particulate emissions in the case of replacing in-field biomass burning with WOR for EoL biomass management-a desirable outcome for local communities affected by poor air quality, and a potential source of economic incentives for growers through programs like California's Healthy Soils Initiative (CDFA 2020). The SPARCS-LCA model allows for a much more precise quantification than possible in previous analyses of GHG benefits traded off for pollution benefits. Similarly, decreased GHG and pollutant emissions are traded for increased freshwater use in flood irrigation versus drip and microsprinkler irrigation. However, the increased water use and reduced application efficiency of flood irrigation may contribute to groundwater recharge in certain regional contexts - an outcome supported by California's Sustainable Groundwater Management Act (California State Assembly 2006).

Elucidation and quantification of such tradeoffs has been made possible by the development of the SPARCS-LCA model and its parameterization with temporally and spatially specific data, as well as its capacity to account for the agronomic effects of management and input choices on yield and biomass accumulation. The SPARCS-LCA model also supports streamlined sensitivity calculations, providing a reference (Tables S9-S10 of the supplementary material) for evaluation of marginal changes in orchard environmental performance in response to changes in management-e.g., for every $1 \%$ decrease in tree loss rate, this model predicts a $0.1 \%$ decrease in orchard GHG footprint on a per kg kernel basis. This resource has the potential to provide valuable policy support for California's statewide efforts to promote sustainable agriculture and protect the environment, and to provide the almond industry with information on where to improve or focus research.

This study has highlighted a number of best-practice options for life cycle modeling of agricultural industries at regional scales, and a number of "hotspots" for environmental impacts in the California almond industry. In particular, a consistent accounting of orchard productivity and biomass co-product utilization has revealed significant environmental benefits associated with this and potentially other cropping systems, which must be included in a complete assessment of environmental performance. Quantification of spatial variation in management practices and inputs as well as the environmental and infrastructural context of production-especially regarding biomass co-product utilization and irrigation energy demandis herein demonstrated as vital to assessment of the environmental burden of agricultural production.
Although regionally specific LCI data were not available for every input accounted for in this analysis, this study has endeavored to use the most appropriate substitutes available. Given the large number of inputs and the relatively minor impact of any given input LCI when compared to major impact drivers such as irrigation, biomass fate, and on-site management practice, it is not expected that such LCI substitutions will have a significant effect on overall findings by growing region or for the California almond industry as a whole. Conversely, leaving out inputs or processes for which the ideal LCI is not available might be expected to result in underestimation of overall impacts. This study elects to use imperfect data where necessary rather than tacitly assuming any of the examined processes result in no impacts by leaving them out.

The SPARCS-LCA model is used here to generate impact results using both attributional and consequential approaches for co-product allocation, with economic allocation and substitution, respectively, used to account for the biomass co-products that represent an important component of this agro-industrial ecosystem. The attributional approach fails to account for the significant interactions of almond biomass co-products-especially EoL biomass and almond hull-with California's environment and industrial landscape. Specifically, almond hulls provide a significant component of the California dairy cattle diet that would otherwise drive production of additional alfalfa or other feed crops, while EoL biomass and some post-harvest biomass components are an important fuel source for the California electricity grid and effectively substitute some portion of energy sector fossil $\mathrm{CO}_{2}$ emissions with biogenic $\mathrm{CO}_{2}$ emissions which can be considered carbon neutral. In order to capture these interactions in assessment of almond production practices, a consequential approach is required. These findings, along with generation of spatially resolved reference LCIs for California almond production, related agricultural services and products (i.e., pollination, alfalfa) and environmental impact response equations for a wide range of model parameters, demonstrate the flexibility and utility of this novel model framework for agricultural LCA.

Supplementary Information The online version contains supplementary material available at https://doi.org/10.1007/s11367-021-01891-4.

Open Access This article is licensed under a Creative Commons Attribution 4.0 International License, which permits use, sharing, adaptation, distribution and reproduction in any medium or format, as long as you give appropriate credit to the original author(s) and the source, provide a link to the Creative Commons licence, and indicate if changes were made. The images or other third party material in this article are included in the article's Creative Commons licence, unless indicated otherwise in a credit line to the material. If material is not included in the article's Creative Commons licence and your intended use is not 
permitted by statutory regulation or exceeds the permitted use, you will need to obtain permission directly from the copyright holder. To view a copy of this licence, visit http://creativecommons.org/licenses/by/4.0/.

\section{References}

Alaphilippe A, Boissy J, Simon S, Godard C (2016) Environmental impact of intensive versus semi-extensive apple orchards: use of a specific methodological framework for Life Cycle Assessments (LCA) in perennial crops. J Clean Prod 127:555-561

Almond Board of California (ABC) (2019) California Almond Sustainability Program. https://www.sustainablealmondgrowing. org/. Accessed 24 Jul 2019

Bartzas G, Komnitsas K (2017) Life cycle analysis of pistachio production in Greece. Sci Total Environ 595:13-24

Bartzas G, Vamvuka D, Komnitsas K (2017) Comparative life cycle assessment of pistachio and apple production. Inf Process Agric 4:188-198

Beccali M, Cellura M, Iudicello M, Mistretta M (2010) Life cycle assessment of Italian citrus-based products - sensitivity analysis and improvement scenarios. J Env Manag 91(7):1415-1428

Bessou C, Basset-Mens C, Latunussa C, Vélu A, Heitz H, Vannière H, Caliman J-P (2016) Partial modelling of the perennial crop cycle misleads LCA results in two contrasted case studies. Int J Life Cycle Ass 21:297-310

California Natural Resources Agency (2019) Periodic groundwater level measurements. https://data.cnra.ca.gov/dataset/periodicgroundwater-level-measurements. Accessed 25 Nov 2019

California State Assembly (2006) Global Warming Solutions Act of 2006. Sacramento, CA

California Air Resources Board (CARB) (2019) CARB Pollution Mapping Tool: https://ww3.arb.ca.gov/ei/tools/pollution_map/. Accessed 7 Nov 2018

California Department of Food and Agriculture (CDFA) (2018) 2017 California Almond Acreage Report. Sacramento, CA

California Department of Food and Agriculture (CDFA) (2020) Healthy Soils Program. The Office of Environmental Farming and Innovation : https://www.cdfa.ca.gov/oefi/healthysoils/. Accessed 6 Dec 2019

Clark N, Frate CA, Sumner DA, Klonsky K, Stewart D, Gutierrez C (2016) Sample costs to establish and produce alfalfa: Tulare County, Southern San Joaquin Valley, 300 acre planting. University of California Cooperative Extension, Davis, CA

Del Borghi A (2013) LCA and communication: environmental product declaration. Int J Life Cycle Ass 18:293-295

De Menna F, Vittuari M, Molari G (2015) Impact evaluation of integrated food-bioenergy systems: a comparative LCA of peach nectar 73:48-61

Deng J, Salas W (2017) Improving DNDC modeling capability to quantify mitigation potential of nitrous oxide from California agricultural soils. Sacramento, CA: CARB. https://ww3.arb.ca. gov/research/apr/past/14-306.pdf. Accessed 6 May 2018

Duncan RA, Holtz BA, Doll DA, Klonsky K, Sumner DA, Gutierrez CA, Stewart DE (2016) Sample costs to establish an orchard and produce almonds: San Joaquin Valley North micro sprinkler irrigation. University of California Cooperative Extension, Davis, CA

Egea G, Nortes PA, Gonzalez-Real MM, Baille A, Domingo R (2010) Agronomic response and water productivity of almond trees under contrasted deficit irrigation regimes. Agr Water Manag 97:171-181

EPD International (2020) The International EPD System. https:// www.environdec.com/. Accessed 26 Nov 2019
Fulton J, Norton M, Shilling F (2019) Water-indexed benefits and impacts of California almonds. Ecol Indic 96:711-717

Giudice A, Mbohwa C, Clasadonte MT, Ingrao C (2013) Environmental assessment of the citrus fruit production in Sicily using LCA. Ital J Food Sci 25(2):202-212

Goldhamer DA, Fereres E (2017) Establishing an almond water production function for California using long-term yield response to variable irrigation. Irrig Sci 35:169-179

Google Earth Pro V. 7.3. (2019) Image Landsat/ Copernicus. California. Accessed 4 Apr 2019

Goulds Water Technology (2019) Goulds Water Technology: a xylem brand. Turbine Catalog: Performance Curves: http://goulds.com/ turbine-catalog/. Accessed 24 May 2019

Holtz BA, Doll DA, Browne G (2014) Whole almond orchard recycling and the effect on second generation tree growth, soil carbon, and fertility. XXIX International Horticultural Congress on Horticulture: Sustaining Lives, Livelihoods, and Landscapes (pp. 315-320). IHC2014.

Hyles T (2017) The water-electricity nexus in California: droughtinduced risk to thermal electricity generation. Masters Thesis, Arcata, CA.

Ingrao C, Matarazzo A, Tricase C, Clasadonte MT, Huisingh D (2015) Life cycle assessment for highlighting environmental hotspots in Sicilian peach production systems. J Clean Prod 92:109-120

Jenkins BM, Turn SQ, Williams RB, Goronea M, Abd-el-fattah H (1996) Atmospheric pollutant emission factors from open burning of agricultural and forest biomass by wind tunnel simulations:, vol 1. CARB, Sacramento, CA

Kendall A (2012) Time-adjusted global warming footprints for LCA and carbon footprints. Int J Life Cycle Ass 17:1042-1049

Kendall A, Marvinney EM, Zhu W, Brodt SB (2015) Life cycle-based assessment of energy use and greenhouse gas emissions in almond production, part I: analytical framework and baseline results. J Ind Ecol 19:6

Kendall A, Yuan J, Brodt SB (2013) Carbon footprint and air emission inventories for US honey production: case studies. Int J Life Cycle Ass 18(2):392-400

Kimmelshue JE, Heilmann MH, Wang Z, Mulder S, Stall C (2014) Almond industry maps: a comprehensive, living map of California almonds. https://www.almonds.com/growers/resources/crop-forecasts/ tc-almond-industry-maps. Accessed 18 Jan 2019

Long R, Leinfelder-Miles M, Putnam D, Klonsky K, Stewart D (2015) Sample costs to establish and produce alfalfa hay in the Sacramento Valley and Northern San Joaquin Valley: flood irrigation. University of California Cooperative Extension, Davis, CA

Longo S, Mistretta M, Guarino F, Cellura M (2017) Life cycle assessment of organic and conventional apple supply chains in the North of Italy. J Clean Prod 140:654-663

Majeau-Bettez G, Dandres T, Pauliuk S, Wood R, Hertwich E, Samson R, Strømman AH (2018) Choice of allocations and constructs for attributional or consequential life cycle assessment and input-output analysis. J Ind Ecol 22:656-670. https://doi.org/10.1111/jiec.12604

Marvinney EM, Kendall AM, Brodt SB (2015) Life cycle-based assessment of energy use and greenhouse gas emissions in almond production, part II: scenario and sensitivity analysis. J Ind Ecol 19(6)

Medellín-Azuara J, Howitt RE, MacEwan DJ, Lund JR (2011) Economic impacts of climate-related changes to California agriculture. Clim Change 109(S1):S387-S405

Mekonnen MM, Hoekstra AY (2011) The green, blue and grey water footprint of crops and derived crop products. Hydrol Earth Syst Sci Discuss 15(5):1577-1600

Milà i Canals L, Burnip GM, Cowell S, (2006) Evaluation of the environmental impacts of apple production using life cycle assessment (LCA): case study in New Zealand. Agric Ecosyst Environ 114(2-4):226-238 
Nicolò BF, De Salvo MC, Ramirez-Sanz C, Estruch V, Sanjuan N, Falcone G, Strano A (2018) Life cycle assessment applied to different citrus farming systems in Spain and Italy. Agroecol Sust Food 42:1092-1105

Nikkhah A, Royan M, Khojastehpour M, Bacenetti J (2017) Environmental impacts modeling of Iranian peach production. Renew Sust Energ Rev 677-682.

O'Geen AT, Saal MB, Dahlke HE, Doll DA, Elkins RB, Fulton A, Walkinshaw $\mathrm{M}$ et al (2015) Soil suitability index identifies potential areas for groundwater banking on agricultural lands. Calif Agr 69(2):75-84

PE International (2019) GaBi ts 6.0: system software and databases for life cycle engineering. Leinfelden-Echterdingen, Germany: PE International.

Poore S, Nemecek T (2018) Reducing food's environmental impacts through producers and consumers. Science 360(6392):987-992

Pope KS, Lightle DM, Buchner RP, Niederholzer F, Klonsky K, Sumner DA, Gutierrez CA et al (2016) Sample costs to establish an orchard and produce almonds: Sacramento Valley micro-sprinkler irrigation. University of California Cooperative Extension, Davis, CA

Raschio G, Smetana S, Contreras C, Heinz V, Mathys A (2018) Spatiotemporal differentiation of life cycle assessment results for average perennial crop farm: a case study of Peruvian cocoa progression and deforestation issues. J Ind Ecol 22:1378-1388

Robinson PH (2015) Almond hulls as a dairy feed. University of California Cooperative Extension, Davis, CA

Rosa D, Figueiredo F, Castanheira EG, Freire F (2017) Lifecycle assessment of fresh and frozen chestnut. J Clean Prod 140:742-752

Sanjuán N, Ubeda L, Clemente G, Mulet A, Girona F (2005) LCA of integrated orange production in the Comunidad Valenciana (Spain). Int J Agric Resour Gov Ecol 4(2):163-177

United Nations Food and Agriculture Organization (UNFAO) (1989) Irrigation water management: irrigation scheduling. Annex I: irrigation efficiencies: http://www.fao.org/3/t7202e/t7202e08. htm. Accessed 18 Jul 2018
United States Department of Agriculture National Agricultural Statistics Service (USDA NASS) (2019) Cropscape. Retrieved from Cropland Data Layer: https://nassgeodata.gmu.edu/CropScape/. Accessed 18 Sept 2019

United States Department of Agriculture National Agricultural Statistics Service (USDA NASS) (2019) Statistics by State. https:// www.nass.usda.gov/Statistics_by_State/California/Publications/ AgComm/index.php. Accessed 4 May 2019

United States Department of Agriculture (USDA) (2017) Tree nuts: world markets and trade. Washington, D.C.

United States Environmental Protection Agency (USEPA) (2017) Tool for Reduction and Assessment of Chemicals and Other Environmental Impacts (TRACI). https://www.epa.gov/chemical-research/ tool-reduction-and-assessment-chemicals-and-other-environmentalimpacts-traci. Accessed 8 Jan 2017

Volpe R, Messineo S, Volpe M, Messineo A (2015) Carbon footprint of tree nuts based consumer products. Sustainability 7:14917-14934

Winans K, Marvinney EM, Gillman A, Spang E (2020) An evaluation of on-farm food loss accounting in life-cycle assessment (LCA) of four California specialty crops. Front Sustain Food Sys 4:10-24

Wolff M, Guo L (2019) Whole orchard recycling: inclusion in the CDFA healthy soils incentive program. CDFA, Sacramento, CA

Water Use in Life Cycle Assessment (WULCA) (2018) AWARE: consensus-based method development to assess water use in LCA: http://www.wulca-waterlca.org/aware.html. 19 October 2019

Yaghmour M, Haviland DR, Fichtner EJ, Sanden BL, Viveros M, Sumner DA, Gutierrez CA et al (2016) Sample costs to establish an orchard and produce almonds: San Joaquin Valley South doubleline drip irrigation. University of California Cooperative Extension, Davis, CA

Publisher's Note Springer Nature remains neutral with regard to jurisdictional claims in published maps and institutional affiliations. 